\title{
ACERCA DE LOS DECRETOS LLAMADOS DE URGENCIA Y DE LA ADECUACION A SUS CARACTERES Y PECULIAR NATURALEZA SIN NECESIDAD DE UNA PREVIA REFORMA CONSTITUCIONAL (*)
}

\author{
Luis Felipe Cantuarias Salaverry \\ Sergio Oquendo Heraud
}

Hace unos meses, a propósito de haber llevado un curso en común sobre derechos económicos en la Facultad de Derecho de la PUCP, los autores de este trabajo dirigimos nuestra preocupación a los decretos supremos de urgencia.

El haber acogido nuestra Constitución de modo sui géneris tal facultad legislativa en manos del Presidente, así como el uso abusivo que de ella han hecho nuestros gobernantes, hace impostergable no ya una correcta interpretación, sino una reglamentación que obligue al Ejecutivo a ceñirse a los caracteres propios de la decretación de urgencia cuando a ésta deba recurrirse. Más allá de esto, especial análisis merecerá el posible control constitucional de la legislación de emergencia que contravenga la Constitución.

La inquietud señalada se manifiesta hoy en el presente informe, que pretende dilucidar la naturaleza jurídica de los decretos supremos de urgencia a la luz de la doctrina y la práctica legislativa; así como de las prerrogativas similares establecidas en otros sistemas políticos. A partir de esto, se pondrá el acento en los grandes problemas políticos y jurídicos, tentándose propuestas de solución.

(*) El presente estudio es una versión corregida y aumentada de uno anterior que obtuviera el primer puesto-en el Concurso de Ensayo Jurídico para Estudiantes convocado por la Facultad de Derecho de la Universidad Católica, durante el primer semestre de 1990. 
Somos conscientes de que nuestra aún joven democracia requiere de controles y contrapesos claramente delineados que impidan arbitrariedades y excesos en el uso del poder, máxime cuando nuestra Constitución, como veremos en su momento, ha establecido un sistema político eminentemente presidencialista.

Sólo nos resta añadir, a este respecto, que siendo el presente un trabajo colectivo en el que resulta imposible diferenciar los aportes individuales de cada quien, optamos por condenarnos mutuamente.

\section{ANALISIS GENERAL DEL SISTEMA POLITICO Y DEL REGIMEN POLITICO PERUANOS: UN PRESIDENTE CON CORONA}

La Constitución de 1979 instituye un sistema democrático-representativo. Algunos analistas - como el Dr. Enrique Chirinos Soto (1) - consideran que ha seguido la tradición de la forma republicana de gobierno, en donde las notas características de su calidad de democrática y representativa están en la delegación popular, en representantes libremente elegidos, de los derechos de gobernar y votar las leyes. Esta visión tradicional es cuestionada por algunos constitucionalistas que, como Francisco Eguiguren Praeli (2), sostienen más bien que nuestro sistema constitucional constituye un "modelo abierto", en donde junto a una democracia formal y restringida, existen una serie de preceptos que permiten aplicaciones muy diversas según el régimen político del que se trate.

Más allá de estas disquisiciones, nos interesa subrayar que nuestra democracia representativa es una fundamentalmente electoral, en la medida que la participación popular se encuentra casi exclusivamente limitada a la elección, cada cinco años, del Presidente y de los representantes parlamentarios. Una vez elegidos, éstos

(1) CHIRINOS SOTO, Enrique. La nueva Constitución al alcance de todos. AFA Editores, tercera edición. Lima, 1984.

(2) EGUIGUREN PRAELI, Francisco. El fortalecimiento de las funciones legislativas del gobierno: decretos legislativos y decretos presidenciales de urgencia. En: La Constitución peruana de 1979 y sus problemas de aplicación. Cultural Cusco Editores. Lima, 1987, p. 395 y ss. 
reciben una suerte de "cheque en blanco", toda vez que pueden ejercer el poder con prescindencia de la opinión de quien se los otorga.

La poca participación ciudadana en los procesos de decisión política se expresa con mayor claridad todavia en el régimen político peruano. En efecto, sin dejar por completo de lado algunas prerrogativas del Parlamento, se concentra innúmeras facultades en el Poder Ejecutivo.

Siguiendo a Maurice Duverger -quien distingue entre regímenes parlamentarios y presidenciales- el modelo peruano, a pesar de ser mixto, pues confiere preeminencia al Congreso sobre el Ejecutivo en lo que a atribuciones se refiere, se acerca más a un régimen presidencialista. Tal aserto se colige del hecho que si bien el Presidente de la República es elegido por sufragio universal y directo, concentra una serie de poderes propios que exceden largamente a los que corresponderian a un presidente bajo un régimen parlamentarista -en donde aquél y su gabinete provienen del Parlamento.

El modelo político peruano -que forma parte de lo que García Belaunde ha calificado como presidencialismo latinoamericano (3)establece, no obstante lo anotado, un sistema de contrapesos a los poderes del Ejecutivo, como son el control parlamentario y la facultad de la Cámara de Diputados de interpelar y censurar ministros.

La tradición peruana de un Ejecutivo vigoroso responde a la creencia que frente a la complejidad de la vida republicana, un

(3) "En cuanto a los rasgos del modelo (peruano), es difícil decir dónde ubicarlo. En efecto, no es estrictamente parlamentario ni tampoco presidencial, por lo menos en su sentido clásico. Más bien, podría ser calificado como semipresidencial, o mejor aún, como presidencialismo atenuado o atemperado, toda vez que, por encima de sus incrustaciones parlamentarias, que vienen, como queda dicho, del siglo pasado, el peso de todo el sistema recae en el Presidente de la República, por lo que bien podríamos hablar de la existencia de un presidencialismo sin más o de un presidencialismo latinoamericano". (GARCIA BELAUNDE, Domingo. Funciones legislativas del Ejecutivo moderno: el caso peruano. En: Lecturas sobre temas constitucionales 3. Comisión Andina de Juristas. Lima, 1989, pp. 23-24). 
órgano eficiente, expeditivo y homogéneo - según palabras de José Pareja Paz Soldán (4) - resulta indispensable para conjurar los problemas nacionales. Ello se apoya en la verificación de la tendencia nacional al paternalismo político y a la primacía de los carismas personales por sobre las cuestiones ideológicas en las contiendas electorales. Simultáneamente, se fortalece al Ejecutivo para evitar la indefinición de competencias que siempre nos han llevado a crisis políticas, en donde el llamado a los cuarteles no se ha hecho esperar.

Quizás por estas consideraciones, los Constituyentes de 1979 decidieron dar marcha atrás al tenue parlamentarismo de la Constitución de 1933, y reforzar, en cambio, las facultades del Ejecutivo. No se llegó a un sistema presidencial puro - como el que existe, por ejemplo, en los Estados Unidos- pero arribamos a un régimen mixto o semipresidencial unido por vínculos de sangre a la Constitución Francesa de la Quinta República (1958). Sin duda, un Presidente con corona.

En el sistema semipresidencial, el Jefe de Estado reúne poderes excepcionales y personalmente no está sometido al control del Parlamento. Cosa distinta ocurre con los ministros, quienes son responsables individualmente no sólo por sus actos, sino también por los presidenciales que refrendan; razón por la cual el Parlamento puede interpelarlos y censurarlos. Esto es, que el Presidente carece de responsabilidad política.

Como podrá apreciarse, la estabilidad de un régimen de esta naturaleza depende de que el gobierno cuente con mayoría parlamentaria, situación que se dio en Francia a partir del ascenso constitucional al poder del general De Gaulle.

La tendencia actual en el Derecho Constitucional Comparado, de otra parte, es a reforzar la autoridad del Ejecutivo; situación que se presenta incluso en los regímenes de tipo parlamentario. Las Constituciones de España, Cuba y Ecuador parecen confirmar esta afirmación.

(4) vid. PAREJA PAZ SOLDAN, José. Derecho constitucional peruano y la Constitución de 1979. Ediciones Justo Valenzuela, tercera edición. Lima, 1984, pp. 199 y ss. 
El artículo 201 de la Constitución Política del Perú señala que el Presidente de la República es el Jefe del Estado y personifica a la nación. A su vez, el artículo 211 señala las atribuciones del primer mandatario, cuyo inciso tercero prescribe que éste dirige la política general del gobierno. Si bien es cierto que muchas de las funciones gubernativas se les encarga a los ministros, dejándose al Presidente las funciones superiores, la responsabilidad corporativa en la dirección de los designios del país no afecta en nada la autoridad del Jefe de Estado.

Resulta curioso que el artículo 201 consigne que "el Presidente personifica a la nación". Tal atributo es propio de los monarcas, quienes ungidos por la gracia divina no sólo la personificaban, sino que manejaban la nación a su mero arbitrio. Esto resulta incompatible con la idea de una moderna democracia, incluso en las llamadas "monarquías republicanas". El Presidente de la República representa por excelencia a la nación peruana, pero sólo el pueblo puede personificarla.

El fortalecimiento de las atribuciones presidenciales por nuestro régimen político no se ha manifestado en un ejercicio signado por un equilibrio entre los poderes del Estado. Los gobiernos del arquitecto Fernando Belaunde Terry y del doctor Alan García Pérez sucumbieron a la tentación de aprovechar sus mayorías parlamentarias para obtener facultades delegadas o para arrogarse la capacidad de emitir decretos supremos con efectos de leyes; abusando de esta manera del artículo 211 inciso 20 de la Constitución. Costumbre que, no obstante la precaria mayoría parlamentaria obtenida por el partido de gobierno gracias a alianzas, el actual Presidente, ingeniero Alberto Fujimori, pretende reeditar.

Y es precisamente tal uso arbitrario de los decretos de necesidad y urgencia, lo que hace manifiesto el fortalecimiento del Ejecutivo del que hemos venido hablando. El inciso 20 ha sido y es la gran puerta a través de la cual el gobierno ha legislado sobre materias que se encuentran fuera de su competencia, argumentándose una urgencia que no siempre era tal. Todo esto ha distorsionado la orientación de la Carta Política, pues el Ejecutivo ha usurpado facultades legislativas que no posee. 
2. FACULTADES LEGISLATIVAS EXTRAORDINARIAS DEL, PODER EJECUTIVO: LOS DECRETOS DE NECESIDAD Y URGENCIA

\subsection{La institución en el Derecho Comparado}

La facultad concedida al Presidente de emitir, en determinadas circunstancias, medidas extraordinarias en materia económica y financiera constituye una institución novedosa en nuestra dogmática constitucional. Sin embargo, la plasmación de tal instituto en la Constitución de 1979 permite observar la existencia de gruesas deficiencias que implican un resquebrajamiento en su coherencia sistemática; deficiencias que se han hecho particularmente notorias en la práctica legislativa de los últimos años.

El perfil de nuestro modelo, en este sentido, aparece escasamente definido e inconvenientemente confuso en la normatividad constitucional. Por ello, coincidimos con Francisco Eguiguren en la necesidad de recurrir al estudio del tratamiento legislativo que ha recibido la institución en otros países, para así desentrañar sus reales caracteres.

La institución que analizamos existe en Constituciones como la francesa, española y la italiana, pero en todos los casos -como sostiene el profesor Enrique Bernales (5) - "el legislador se ha cuidado de que no sea una facultad ad libitum del Jefe de Estado". Así, se requiere la concurrencia de varias condiciones: que exista una situación objetiva, grave e inmediata que configure la necesidad y la urgencia de actuar por esta vía; que la interven ción del Presidente sea supletoria a la del Parlamento, que por la celeridad que el hecho demanda se vería impedido de actuar de manera eficaz; y que la medida esté sometida a ratificación posterior del Parlamento, a partir de la cual recién tiene eficacia definitiva.

(5) BERNALES BALLESTEROS, Enrique. El funcionamiento del sistema político de la Constitución de 1979. En: La Constitución diez años después. Fundación Friedrich Naumann, primera edición. Lima, 1989, p. 150. 


\section{a) Sistema francés}

La Constitución francesa de 1958 establece que la procedencia de las medidas de carácter extraordinario depende del criterio del Presidente, aunque su constitucionalidad está sujeta a la concurrencia copulativa de dos requisitos, que son: la existencia de una grave e inminente amenaza a la seguridad interna o a la estabilidad política; y la incapacidad material de los poderes públicos y los órganos constitucionales para enfrentar la situación mediante sus tradicionales atribuciones legislativas.

El artículo 16 de la Constitución francesa, como bien ha señalado Eguiguren (6), contempla una suerte de "dictadura temporal" porque "no restringe o delimita el tipo y contenido de las medidas legislativas que podrá dictar el Presidente; la misma norma postula que tales medidas deben dirigirse a procurar el pronto y pleno funcionamiento de los poderes públicos constitucionales".

\section{b) Sistema español}

En la Constitución española de 1978, las medidas extraordinarias de necesidad y urgencia adquieren la forma de "decretos-leyes", constituyendo normas con rango de ley. Su contenido es específico, y no pueden en ningún caso regular aspectos referidos a instituciones fundamentales del Estado, a los derechos, deberes y libertades de los ciudadanos, al régimen de las Comunidades Autónomas o a los derechos electorales.

$\mathrm{El}$ instituto de los decretos con fuerza de ley no es, sin embargo, nuevo en la península ibérica. Estaba contemplado en la Ley de Cortes, que fue objeto de varias reformas a lo largo del siglo, y que contemplaba una figura similar, aunque menos

(6) EGUIGUREN PRAELI, Francisco. Los decretos de necesidad y urgencia en relación a la atribución presidencial de dictar medidas extraordinarias contenida en el inciso 20 del artículo 211 de la Constitución. En: Derecho, № 40, diciembre de 1986. Fondo Editorial de la PUC, Lima, p. 172 y ss. 
delimitada que la que consigna hoy la Constitución española (así, por ejemplo, no se establecía su provisionalidad). El artículo 13, párrafo 1 de la referida Ley de Cortes disponía que "En caso de guerra o por razones de urgencia, el Gobierno podrá regular mediante Decreto-ley, las materias enunciadas en los artículos 10 y 12" (que se referían a materias reservadas a Ley) (7).

El artículo 86 (8) de dicho cuerpo de leyes prescribe que podrán dictarse estas normas en caso de "extraordinaria y urgente necesidad", bajo la forma de Decreto-ley. El Poder Ejecutivo es quien tiene la facultad de calificar qué hechos configuran la urgencia, pero se exige que deben mediar situaciones objetivas de urgente necesidad.

Nota singular del modelo español es el carácter

(7) vid. SALAS, Javier. Los Decreto-leyes en el ordenamiento juridico español. En torno a la urgencia. En: Revista de administración pública. № 51, Instituto de Estudios Políticos. Madrid, 1966, pp. 41-96.

(8) El artículo 86 de la Constitución española de 1978 prescribe que "En caso de extraordinaria y urgente necesidad, el gobierno podrá dictar disposiciones legislativas provisionales que tomarán la forma de decretos-leyes..." (Tomado de ZOLEZZI MOLLER, Armando. El inciso 20 del artículo 211 de la Constitución y la tributación. En: Revista del Instituto Peruano de Derecho Tributario. № 10, junio de 1986).

EGUIGUREN (Op.cit., pág. 173) sostiene que "... el Parlamento tendrá que pronunciarse expresamente sobre la conversión en ley o derogación del decreto". Consideramos que la derogatoria sólo podria proceder si el decreto, una vez ratificado, es cesado en sus efectos. La no convalidación congresal haría caducar la norma, no la derogaría como veremos en su momento. De otra parte, la doctrina española expresamente sostiene que la convalidación parlamentaria no tiene por efecto convertir en ley al decreto, sino la de transformarlo de provisional en definitivo. (vid. ASTARLOA HUARTE-MENDICOA, Ignacio. Teoría y práctica del Decreto-ley en el ordenamiento español. En: Revista de ad. ministración pública. № 106. Centro de Estudios Constitucionales. Madrid, 1985, pp. 97-169. En igual sentido, ALEGRE AVILA, Juan Manuel. La viabilidad constitucional del Decreto-ley en materia tributaria y la regulación del derecho de propiedad. En: Revista de administración pública. № 105,1985, p. 93, en donde cita la sentencia 
provisional de las medidas de emergencia con rango de ley, toda vez que ni bien son dictadas deben ser sometidas a la convalidación del Congreso, dentro del plazo de 30 días de su promulgación. El Congreso, que de no estarlo se reunirá al efecto, dispondrá si convalida o no la medida adoptada. La convalidación, a su turno, es la que le otorga eficacia definitiva a la medida; de no mediar la intervención parlamentaria, la norma quedará sin vigor (9).

El régimen jurídico de la decretación de urgencia gira, como afirma Astarloa Huarte-Mendicoa, en torno a tres pilares: "... la concurrencia de un presupuesto habilitante tasado, que se cifre en una necesidad de carácter extraordinario y urgente; la existencia de límites materiales que ni siquiera en las circunstancias anteriores pueden ser invadidos por decretos con fuerza de ley del gobierno; por último, el reconocimiento de un doble mecanismo de control por el Tribunal Constitucional y las Cortes Generales, quedando a la voluntad de estas últimas la facultad de ratificar o derogar (sic) la decisión gubernativa" (10).

del Tribunal Constitucional del 31 de mayo de 1982, que establece que la convalidación sólo implica cumplir el requisito constitucional para darle al decreto pervivencia en el tiempo; pero, en ningún caso, cambiar su naturaleza jurídica). Más adelante volveremos sobre este tema.

(9) La convalidación del decreto no lo convierte, como ya vimos, en ley. El acto de convalidación toma la forma de una resolución firmada por el Presidente del Congreso, por la que se ordena la publicación del acuerdo de la cámara de diputados. Entonces, formalmente no es una ley, como tampoco lo es materialmente, dado que es decidido por una sola cámara y que su contenido no es regulador de situaciones jurídicas. Del mismo modo, se admite que la denegatoria del Congreso de Diputados tiene efectos ex-nunc y no retroactivos, a diferencia de lo que sucede en Italia. (vid. ASTARLOA, op.cit., pp. 153-155).

(10) ASTARLOA. Teoría y práctica del Decreto-ley en el ordenamiento español.Op.cit., p. 103. 


\section{c) Sistema italiano}

La Constitución italiana de 1947 hace referencia, en su artículo 77 (11), segundo y tercer párrafos, a las "ordenanzas de necesidad".

Participa el sistema italiano de los caracteres anotados, aunque merece especial atención el hecho que, de no ser convertidas en leyes dentro de los 60 días de su publicación, las mencionadas ordenanzas perderán todo efecto desde el principio. Ello no obstante, se establece que el Congreso tendrá la facultad de regular, mediante ley, el contenido de aquellas ordenanzas que no hayan sido "convertidas en leyes". Esta previsión tiene sentido en el sistema italiano, toda vez que en la medida que la no convalidación quita efectos retroactivamente a la fecha de expedición a las ordenanzas, podría haberse generado una serie de relaciones jurídicas a su amparo que, de no resolverse su situación jurídica, generarían gran incertidumbre.

Del mismo modo, la ratificación parlamentaria tiene el efecto de convertir en leyes formales a las ordenanzas de necesidad -mediante una "ley de conversión"-, característica no compartida por los demás modelos.

(11) Artículo 77: "El gobierno no puede, sin delegación de las cámaras, dictar decretos que tengan valor de ley ordinaria. Cuando en casos extraordinarios de necesidad y urgencia el gobierno ?dopte, bajo su responsabilidad, medidas provisionales con fuerza de ley, deberá presentarlas el día mismo para su convalidación (conversión en ley) a las cámaras, que incluso si se hallan disueltas, serán convocadas al efecto y se reunirán dentro de los 5 días. Los decretos perderán toda eficacia (desde el principio) si no se convierten en ley dentro de los 60 días de su publicación. Las cámaras pueden, sin embargo, regular mediante ley las relaciones jurídicas surgidas sobre la base de decretos no convalidados". (Según la traducción de Leyes constitucionales. Editorial Taurus, Madrid, 1959. Los añadidos entre paréntesis corresponden a otras traducciones, $y$, en cualquier caso, no hacen sino precisar las características particulares de la decretación de urgencia en Italia). 
De similar modo, las otras Constituciones europeas han acogido la institución, como es el caso de la austriaca de 1920 -artículo 18, parágrafos 3,4 y 5-, la búlgara de 1971 -artículo 94, inciso segundo-, la griega de 1975 - artículo 44-y la portuguesa de 1976.

En América Latina, encontramos la Constitución colombiana de 1886, que en sus artículos 121 y 122 , según el texto ordenado por el artículo 43 del acto legislativo No. 1 de 1968, habla de "decretos de emergencia económica y social" (12); la venezolana de 1961 -artículo 190 , inciso 8-; la hondureña de 1982 -artículo 245 inciso 20 , con un texto semejante al de la Constitución peruana-; y la nicaraguense de 1987 -artículo 149, inciso tercero.

\subsection{El caso peruano}

\subsubsection{Antecedentes normativos}

La facultad extraordinaria del Poder Ejecutivo para emitir normas jurídicas sin que exista previamente delegación del Poder Legislativo no es nueva. En el Perú existe un antecedente histórico, que es el decreto supremo del 1ro. de enero de 1948, dictado durante el gobierno de José Luis Bustamante y Rivero y refrendado por su ministro de hacienda, Luis Echecopar Garcia, por medio del que se aprobó el Presupuesto General de la República para el año fiscal de 1948 (13).

(12) Como señala SACHICA, el artículo 121 faculta al gobierno a dictar decretos de emergencia económica y social cuando medien "...situaciones de excepción producidas por perturbaciones ya del orden público material o externo, o bien del orden social o económico". A su vez, el artículo 122 dispone un control especial del ejercicio de dichas facultades excepcionales. A este respecto vid. SACHICA, Luis Carlos. El control de constitucionalidad y sus mecanismos. Editorial Temis S.A., tercera edición. Bogotá, 1988, pp. 51 y ss.

(13) Precisamente una de las ventajas de haberse acogido constitucionalmente a la decretación de urgencia en nuestra Carta de 1979, consiste en haber convertido en potestad jurídica lo que antes se presentaba como una facultad extra o contra constitutionem; superándose con ello los "decretos de hecho". 
A este respecto, Zolezzi (14) consigna que "como el Congreso no sancionó el Presupuesto, entre otras varias consideraciones el Decreto Supremo expresa que 'el Poder Ejecutivo se encuentra ante una situación de hecho que no puede dejar de afrontar sin incurrir en seria responsabilidad'. Se consideró a la situación de emergencia como título habilitante para dictar una medida extraordinaria, sobre materia que, conforme a la Constitución entonces vigente, estaba reservada a ley". (El subrayado es nuestro).

Ya la Constitución de 1933 contemplaba, en sus artículos 40 y 49 , la posibilidad que el Parlamento autorizara al gobierno a dictar normas que establecieran limitaciones a las libertades de comercio e industria, o medidas tendientes a preservar el abaratamiento de los alimentos y las subsistencias, siempre que mediaran circunstancias excepcionales calificadas como de "seguridad y necesidad públicas" en un caso, y "circunstancias de necesidad social" en el otro. Tales preceptos, sin embargo, confundían la legislación delegada con la de emergencia; pero son sin duda una primera aproximación constitucional al tema de las medidas extraordinarias del Ejecutivo (15).

Más recientemente, la Ley 17044 del 20 de abril de 1968 autorizó al gobierno del arquitecto Belaunde a dictar "medidas de carácter extraordinario para dar solución al desequilibrio estructural de las finanzas públicas, para fortalecer la balanza de pagos y para fomentar el desarrollo integral de la economía"(16). Se

(14) ZOLEZZI MOLLER, Armando. Op.cit.

(15) Sobre el particular, vid. EGUIGUREN, op.cit., p. 174.

(16) El artículo único de la Ley 17044, primer y tercer párrafos, establece que "Autorízase al Poder Ejecutivo para que en el plazo improrrogable de 60 días contados a partir de la fecha de la presente ley, y de conformidad con las normas constitucionales, dicte las medidas de carácter extraordinario para dar solución al desequilibrio estructural de las finanzas públicas, para fortalecer la balanza de pagos internacionales del país, y para fomentar el desarrollo integral de nuestra economia". (...) "Las medidas que se dicten en uso de las autorizaciones contenidas en esta ley, se expedirán por Decreto Supremo con el 
estableció, sin embargo, que dichas "medidas extraordinarias" debían ser expedidas mediante decretos supremos con el voto aprobatorio del Consejo de Ministros y con cargo de dar cuenta al Congreso.

Una de las normas dictadas al amparo de esta facultad fue el decreto supremo No. 287-68-HC, de Impuesto a la Renta, que significó una sustantiva reforma del sistema tributario peruano.

Estos antecedentes legislativos reseñados explicarían la fórmula adoptada por el inciso 20 del artículo 211 de la Constitución de 1979, que adolece de una serie de fallas, como son la herramienta normativa utilizada -el decreto supremo- y la imprecisión y vaguedad de la expresión "dar cuenta al Congreso"; además de otras deficiencias que serán materia de posterior análisis.

2.2.2 Práctica legislativa: cuando todos los gobiernos son "liberales"

Desde que la Constitución entró en vigor —el 28 de julio de 1980-, hasta nuestros días, dos gobiernos constitucionales han detentado el poder político. Ambos constitucionales en su origen, ambos igualmente arbitrarios en el uso de medidas por naturaleza excepcionales y restrictivas en su adopción.

Ciertamente nuestra práctica legislativa se ha caracterizado por el uso excesivo de los decretos presidenciales de urgencia. Si hasta julio de 1985 se dictó 667 de ellos, el gobierno del presidente García aumentó un millar. A julio de 1989 —según la investigación que preparara el despacho del Senador Enrique Bernales para la Fundación Eberth, titulada Parlamento y democracia en el Perú - se ha promulgado 1,640 decretos de urgencia. Es decir, que el gobierno aprista a la fecha indicada promulgó 933 de estas normas al amparo del inciso 20 del artículo 211 de la Constitución.

Si bien es cierto que el amparo constitucional de la legislación de urgencia se encuentrajustificado, pues permite disponer

voto aprobatorio de Consejo de Ministros, con cargo de dar cuenta en cada caso al Congreso Nacional". (Tomado de ZOLEZZI, op.cit.). 
de una vía para aquellas situaciones imprevistas que, de no ser así, podrían generar respuestas políticas ajenas a los canales constitucionales, también lo es el que su uso sólo puede estar restringido a las situaciones expresamente contempladas. Incurrir, como lo ha hecho nuestro Ejecutivo, en un cómodo uso del instituto ante crisis de gobierno equivale a incentivar una quiebra institucional; así, el supuesto conjuro de la crisis terminaría profundizándola.

Debemos recordar, una vez más, la excepcionalidad de los decretos de urgencia, como normas primarias e idénticamente eficaces a la ley formal. Si como sucede en el Perú —aunque también en casi todos los países que la acogen-la decretación de urgencia es tan frondosa y expansiva que supera la producción legislativa ordinaria, estaríamos admitiendo en la práctica una colegislación paralela, ajena al espíritu constitucional.

En este sentido, el profesor César Landa Arroyo (17) ha determinado la producción normativa realizada mediante el inciso 20 , artículo 211, en relación a la del Congreso. Así, desde julio de 1980 a julio de 1989 se ha emitido 1639 leyes formales, en tanto que 1601 decretos de urgencia. Pero si tomamos los datos de la investigación llevada a cabo por Bernales, tendríamos que se ha emitido 1640 de ellos.

Si bien las materias tratadas son de lo más diversas -incluyendo aspectos vinculados a vivienda, educación, salud, justicia, trabajo y relaciones exteriores-, ha preponderado las medidas en materia tributaria. La interpretación dada a los alcances de los decretos presidenciales de urgencia ha sido, en la mayoría de los casos, extensiva.

Aun si les atribuyésemos rango de ley, por lo que no resultaría extraño que se regule aspectos reservados a ésta, no

(17) LANDA ARROYO, César. Citado por EGUIGUREN PRAELI, Francisco. Los retos de una democracia insuficiente. Comisión Andina de Juristas/Fundación Friedrich Naumann, primera edición. Lima, 1990, p. 164. 
puede dejarse de lado — como señala Eguiguren (18)— la exigencia de que se trate de medidas extraordinarias, de interés público y de contenido económico y financiero.

El uso indebido de esta facultad excepcional acarrearía que muchas de las normas dictadas a su amparo adolezcan de vicios de ilegalidad al referirse a situaciones de dudosa calificación como de emergencia, que no puedan seguir el trámite ordinario para la promulgación de las leyes sin generar una situación perjudicial. Otro vicio se produciría al interpretar de manera amplia las materias incluidas en el doble requisito de económico-financieras.

No podemos sino concluir con Eguiguren (19) en que el abuso de esta facultad presidencial ha constituido un mecanismo político invalorable para manejar de manera muy libre la economía y la tributación, evitándose de este modo el lento recurso al Congreso para la dación de leyes o la obtención de la facultad legislativa delegada. A fin de cuentas, siempre ha resultado más cómoco operar, incluso a este nivel, en la más absoluta informalidad.

\section{EL REGIMEN JURIDICO DE LA DECRETACION DE URGENCIA}

\subsection{Naturaleza juridica}

Como bien comenta Juan Gascón Hernández (20), ya André Hariou enfocaba el estudio del Decreto-ley como una excepción a la teoría de la ilegalidad de los reglamentos. "En realidad... no es otra cosa que una excepción al principio de legalidad formal"... el cual

(18) EGUIGUREN PRAELI, Francisco. Normas contrarias a la Constitución y la ley. En: Revista del Foro, año LXXI, № 1984-1. Colegio de Abogados de Lima, 1984, p. 99.

(19) EGUIGUREN. Ibidem.

(20) GASCON HERNANDEZ, Juan. Problemas actuales del Decreto-ley. En: Revista de administración pública, № 15. Instituto de Estudios Políticos. Madrid, 1954. 
supone que "... no puede en principio elaborarse (la ley) más que de una cierta forma, es decir, por el órgano legislativo".

Tratemos, en primer término, de determinar cuál es la naturaleza de los decretos presidenciales de urgencia; esto es, si son simples decretos supremos o si, por el contrario, estamos ante normas con rango de ley: Ello nos conduce a dilucidar qué entendemos por ley. Previamente, precisemos que la decretación de urgencia constituye función originaria y privativa del Presidente de la República.

La pirámide normativa -desarrollada a partir de Hans Kelsen por el postkelseniano Merckl- coloca en la cúspide a la Constitución, leyes constitucionales y algunos tratados, y por debajo de ésta, a la ley y las normas con rango de ley; a los decretos, reglamentos y normas de carácter general; y a las normas y resoluciones de carácter particular. Como sabemos, para el primer grupo de normas el principio de supraordinación es el de constitucionalidad; para el segundo el de legalidad; y para el último, los principios de competencia y jerarquía del órgano que las emite.

Nos interesa, a este respecto, el nivel de las normas con rango de ley, pues se trata de establecer cuáles son las diferencias entre la ley en sentido formal y las normas con rango de ley o leyes en sentido material. Por la primera, es ley toda aquella que emana del Parlamento siguiendo el procedimiento que para su aprobación y promulgación establece la Carta Política (Título Cuarto, Capítulo Tercero), lo que significa que la calidad de ley depende del órgano del que provenga. Por las segundas, serán leyes las normas que, por su contenido, versen sobre materias que son de reserva legal, con prescindencia del órgano del que provengan.

En consecuencia, podemos afirmar que todo decreto que trate una materia reservada a ley será ley por su contenido; es decir, ley en sentido material. Para que se dé este tratamiento excepcional es necesario que el sistema jurídico haya establecido un procedimiento especial que soslaye el aspecto formal y valide la norma. 
Coincidimos con García Belaunde (21) en que "el principio de la reserva de la ley debe entenderse hoy en dos sentidos, uno el sentido clásico o estricto, que aún permanece y conserva validez, y otro en sentido moderno o relativo, que es el que se ha abierto paso en los últimos años. Así, en principio, todo articulado constitucional debe desarrollarse por ley formal (más aún cuando el texto positivo a ella se remite continuamente, y por ley debe entenderse ley formal). Pero ello no impide la legislación por parte del Ejecutivo. (...) Así, la reserva de la ley debe verse hoy, sobre todo, como una defensa del estatuto del ciudadano y como un fundamento para fijar un reparto de competencias, pero no como un impedimento para que el Estado cumpla sus fines, como es poder intervenir en la vida económica del país que es, por otra parte, lo que se desprende del modelo de economía social de mercado que la Constitución ha consagrado (art. 115). Claro está que esta posibilidad está siempre condicionada por los supuestos habilitantes, como son la extrema y grave necesidad, y sobre todo la provisionalidad..."

En doctrina son dos los grandes grupos de normas con rango de ley: los decretos legislativos -que requieren de una ley habilitante autoritativa-, y los decretos de urgencia, ordenanzas de necesidad o decretos-leyes. Nos compete ahora referirnos a este segundo grupo.

En el caso peruano, el inciso 20 del artículo 211 de la Constitución establece las "medidas extraordinarias". Al ser el instrumento legal propio del Ejecutivo el decreto supremo, se ha interpretado que es este mecanismo legislativo el apropiado para dictar dichas medidas.

El artículo 211, inciso 11 de la Constitución hace referencia a la facultad del Presidente de reglamentar las leyes sin transgredirlas ni desnaturalizarlas, $y$, en tal sentido, puede dictar decretos y resoluciones. Estamos ante una potestad general del primer mandatario. Cosa distinta ocurre con el inciso 20 del mismo artículo.

(21) GARCIA BELAUNDE, Domingo. Op.cit. págs. 32-33. Aunque el autor hace referencia al tema tributario, sus apreciaciones, creemos, son extensivas a los demás supuestos de la materia económico-financiera. 
En efecto, dicho inciso precisa el carácter extraordinario de medidas en el terreno económico y financiero, con lo cual pareciera indicarse que se trata de asuntos que en circunstancias ordinarias serían materia de ley. Esto se reforzaría con la obligación que existe de dar cuenta al Congreso.

En suma, todo hace pensar que los decretos presidenciales de urgencia tratan materias normalmente reservadas a la ley; por lo que, de acuerdo a su contenido, son leyes en sentido material, esto es, normas con rango de ley.

Creemos, en este nivel, necesario detenernos en un sumario análisis de dos conceptos a los que hemos venido haciendo referencia. El primero de ellos es el rango de ley y el segundo la reserva de ley.

A. RANGO DE LEY. En la doctrina extranjera se ha hecho una distinción entre el rango o valor de ley y la fuerza de ley (22). Aunque la distinción tiene objeto a partir de un análisis de la mención de tales términos en la Constitución española y la Ley del Tribunal Constitucional español -algo similar se ha trabajado en Italia-, resulta interesante precisar lo que se entiende por ellos.

Así, Rubio Llorente (23) manifiesta que "Las expresiones 'rango de ley' y 'valor de ley' parecen englobar, junto con la ley misma, una serie de disposiciones normativas, o incluso de actos, que comparten con ella una característica común. Como tal característica no es ni la de proceder de un mismo órgano (...) ni tampoco la de ocupar el mismo lugar en la jerarquía normativa (...) cabe pensar que este elemento o nota común de las disposiciones de distinto origen en el que el rango o el valor

(22) Sobre este particular vid. RUBIO LLORENTE, Francisco. Rango deley, fuerza de ley, valor de ley. En: Revista de administración pública, № 100. Centro de Estudios Constitucionales. Madrid, 1983; pp. 417-432. El autor es magistrado del Tribunal Constitucional de España.

(23) Ibid., p. 420. 
consisten, estriba sólo en la susceptibilidad, que todas estas imposiciones con rango o valor de ley tienen por igual, de ser sometidas al control de constitucionalidad ante el Tribunal Constitucional". (El subrayado es nuestro).

Como podrá notarse, tal característica es una meramente procedimental. Y resulta de un razonamiento circular - de los que habla Félix Cohen - toda vez que si por el rango entendemos una norma atacable mediante control constitucional concentrado, éste se explica, a su vez, por el rango o valor de ley.

De otro lado, en la doctrina clásica se entendía por fuerza de ley una nota distintiva de la ley por antonomasia, sólo aplicable a la ley dada por el órgano legislativo (Congreso). La fuerza de ley tenía una doble faceta, activa y pasiva. Fuerza activa de la ley, también llamada poder innovador, consistía en la capacidad exclusiva de la ley para modificar cualquier punto del orden jurídico preexistente. A su turno, fuerza pasiva era la resistencia específica de la ley para no ser modificada ni derogada si no por medio de otra ley, esto es, por otra norma dotada de la misma fuerza específica.

De lo dicho fluye que actualmente la fuerza de ley no designa una nota común a todas las leyes o a todas las normas a las que se les atribuye tal fuerza. Por ello, se ha dicho que "...el concepto de 'fuerza de ley' engloba una considerable variedad de fuerzas distintas, con lo que se convierte en un metaconcepto (...) que engloba a distintas disposiciones que tienen muy diferente fuerza de innovar y muy diferente fuerza de resistir, y una disposición puede tener rango de ley sin tener fuerza de ley" (24).

Trasladando esto al sistema peruano, muchas normas con rango o valor de ley carecen de fuerza de ley en su sentido activo. Así, los decretos legislativos, si bien tienen rango legal, entendido éste como la posibilidad de su impugnación vía acción ante el Tribunal de Garantías Constitucionales (TGC), carecen de

(24) Ibid.p. 423. 
fuerza de ley; puesto que sólo son válidos dentro del ámbito que les establece la ley habilitante dada por el Congreso. Con los decretos de urgencia sucedería algo similar, en la medida que su ámbito material se encuentra también muy restringido, como se deduce de su aplicación bajo presupuestos habilitantes especiales y por referirse a materia económico-financiera.

En consecuencia, las normas anotadas carecen de la facultad activa de innovar cualquier punto del orden jurídico que les es preexistente. Como ya se habrá notado, además, estamos atribuyendo a priori a la decretación de urgencia su impugnabilidad ante el TGC, lo que será materia de estudio más adelante.

A pesar de lo dicho, nuestra legislación y doctrina no han trabajado tal sentido de los conceptos de fuerza y rango de ley. De este modo, a lo largo de nuestro estudio utilizamos tales conceptos como sinónimos; esto es, como normas con jerarquía legal o leyes en sentido material.

B. RESERVA DE LEY. El mismo autor citado (25) hace una reseña de lo que se entiende por materia de reserva de ley, que sí resulta pertinente a efectos de nuestra sistemática constitucional. El concepto moderno de reserva de ley es radicalmente distinto del original, que tuvo sentido en la Alemania que compartía funciones legislativas entre el Parlamento y el monarca, que tenía tal facultad de modo originario; y en donde se hacía una distinción, hoy caduca, entre Estado y sociedad.

Nos interesa dilucidar el significado moderno de la reserva de ley. Lo que dicen las distintas construcciones teóricas que al efecto se han levantado es que tal reserva debe contener "todas las decisiones esenciales y politicamente importantes $y$, en especial, las que trazan las líneas básicas y las directrices del orden estatal y social". También se ha dicho que contiene a "la competencia exclusiva para regular los derechos fundamentales", no solamente aquellos que tienen que ver con las libertades del individuo.

(25) Al respecto vid. RUBIO LLORENTE. Op.cit., pp. 428-430. 
De tal manera que lo que caracterizaría a la ley como forma superior de creación de derecho en un sistema democrático, sería su elaboración por el Parlamento por medio de la discusión y las negociaciones entre las diversas fuerzas sociales, con la participación de la opinión pública.

\subsubsection{Un problema de jerarquias}

Como ya hemos visto, la necesidad de encontrar un instrumento tradicional que permitiera viabilizar la facultad legislativa extraordinaria del presidente, trajo como consecuencia que en la práctica se recurra a los derechos supremos.

Esta salida pragmática, sin embargo, creó serias dificultades para diferenciar los decretos de urgencia de los decretos ordinarios, en especial por:

(a) Confundirse en la misma categoría a ambos tipos de normas;

(b) Asignárseles numeración e identificación similar y correlativa, lo cual hace muy difícil su diferenciación; $y$,

(c) En los considerandos de los decretos extraordinarios se omite, en la casi totalidad de casos, acreditar la existencia de una situación de emergencia económica y financiera, estableciéndose tan sólo que se dictan al amparo del manido inciso 20 .

El problema, empero, no acaba allí. Existen aspectos de fondo que crean también dificultades para otorgar a los decretos de emergencia rango de ley.

Así, por ejemplo, Enrique Bernales (26) sostiene que una interpretación sistemática les niega valor normativo equiparable a las leyes. El texto constitucional ha cuidado de señalar de forma expresa y taxativa las normas jurídicas a las que reconoce fuerza de ley: las leyes y las resoluciones legislativas emanadas del Parlamento

(26) BERNALES. Op.cit., p. 151. 
(artículo 186, inciso 1), los tratados (artículo 101) y los decretos legislativos del Poder Ejecutivo dictados previa delegación del Congreso (artículo 188). El silencio de la Constitución -prosigue Bernales- en la asignación de la fuerza de ley para las medidas extraordinarias, no podría ser entendido como un olvido susceptible de ser subsanado mediante una interpretación extensiva.

Otro argumento al que acude el conocido constitucionalista para reforzar su tesis es el hecho que, en el debate de la Asamblea Constituyente, el Partido Popular Cristiano propuso un artículo que incluía a los decretos de urgencia bajo la modalidad de Decretos-leyes. La Asamblea no aceptó tal temperamento. Todo ello hace colegir al autor citado que la única manera de sortear el impase es mediante una reforma constitucional que precise el alcance y la configuración de las medidas extraordinarias.

El profesor Alberto Borea Odría (27) abona la tesis reseñada con un argumento también de peso: el artículo 298 inciso 1, que trata de la Acción de Inconstitucionalidad, omite hacer referencia a los decretos de urgencia, a pesar de enumerar a todas las normas con rango de ley susceptibles de ser impugnadas por esta vía. Se trataría pues de una enumeración taxativa la de la norma anotada, y no de una enunciativa que diese cabida a las medidas que venimos comentando.

Si bien el propio Borea critica la enumeración taxativa del inciso 1 del artículo 298, en tanto considera que debería haberse establecido para todas las normas con rango legal, reconoce su existencia.

Otros constitucionalistas, por el contrario, piensan que los decretos de urgencia deberían tener rango de ley, aunque la Constitución se preste a polémica. Convencidos de la incompatibilidad que existe entre la naturaleza de la.institución y una calificación por debajo de la ley, sostienen la interpretación que les asigna rango de ley material, a pesar de las inteligentes observaciones en contra. A esta línea adherimos.

(27) BOREA ODRIA, Alberto. Exposición en el Colegio de Abogados de Lima sobre el TGC, transcrita en Revista del Foro. 
Por el momento, sin embargo, nos interesa tratar los caracteres esenciales de los decretos presidenciales de urgencia. Volveremos sobre el problema de las jerarquías al plantear nuestro punto de vista.

\subsection{Caracteres de los decretos presidenciales de urgencia}

En doctrina, la institución que comentamos tiene varias características que la hacen una figura propia y distinta de las demás atribuciones legislativas del Poder Ejecutivo. Una completa aproximación a tales caracteres es la que hace María del Rosario Pacheco (28).

De la forma como ha sido tratada la legislación de emergencia en el Derecho Comparado, se desprenden los siguientes caracteres:

(a) Es una atribución propia del gobierno, por lo que generalmente está encargada al Presidente de la República (el jefe de gobierno la tiene en los sistemas parlamentaristas); razón por la cual requerirá refrendación ministerial.

(b) En algunas legislaciones su uso se encuentra restringido a los momentos en que el Congreso no se encuentra reunido; en otras - como la peruana- es posible su uso en cualquier circunstancia, siempre que medie un estado de necesidad y urgencia.

Como indicáramos tangencialmente líneas arriba, para nosotros las medidas de necesidad y urgencia son leyes en sentido material, y al tener su sustento en una situación de emergencia que el sistema formal de dación de leyes no puede cubrir apropiadamente, consideramos que proceden con prescindencia del calendario del Congreso.

(28) PACHECO BARANDIARAN, María del Rosario. Los decretos de urgencia y un vacio en la Constitución de 1979. En: Themis-Revista de Derecho, segunda época. № 6. Lima, 1987, pp. 50 y ss. 
(c) Los decretos de urgencia requieren de un presupuesto de hecho habilitante que es la urgente y excepcional necesidad que debe ser solucionada. La presencia de tal condición está sujeta a la discrecionalidad del gobierno. Ello no obstante, las medidas dictadas al amparo de esta facultad no podrían constituir una amenaza para la nación o para el sistema constitucional como ha señalado el Tribunal Constitucional Español-, pues para estos supuestos existen los regímenes de excepción y los mecanismos de reforma constitucional (29).

La concentración de poderes que tal atribución implica en el gobierno responde a circunstancias urgentes y justificatorias por la necesidad de arribar a soluciones a breve plazo; siempre que se refieran a presupuestos concretos que se ubiquen dentro de la competencia gubernativa.

(d) Algunos ordenamientos constitucionales, como el régimen francés, prescriben la necesidad de que el gobierno someta previamente la medida o la promulgación de ésta a otro órgano del Estado.

(e) Una característica esencial a la naturaleza de los decretos de urgencia es su provisionalidad; esto es, que su eficacia definitiva está condicionada a refrendación por parte del Parlamento. Este carácter pone el acento en el control político.

Casi sin excepción, todos los ordenamientos que han legislado sobre este instituto indican de manera precisa esta competencia del Congreso. Así, de no producirse tal ratificación pierden total eficacia. Ello ocurre pues los decretos de urgencia poseen una eficacia provisional desde su emisión hasta la convalidación parlamentaria, que les otorga el vigor definitivo. De no producirse la ratificación el decreto caducaría, toda vez que el pronunciamiento del Congreso es requisito de eficacia y no de validez. En consecuencia, el decreto observado habría regido provisionalmente hasta la manifestación negativa del Congreso.

(29) Sentencias 6/1983 y 111/1983. En: Boletín de jurisprudencia constitucional, № 23, publicación de las Cortes Generales. Madrid, 1983. 
De haberle expresado su confianza, el decreto tendría una eficacia y una vigencia definitivas.

Esta apreciación, sin embargo, no es unívoca. Para algunas legislaciones, la pérdida de eficacia se retrotrae al momento de la emisión de las medidas de urgencia. Es el caso, por ejemplo, de las "ordenanzas de necesidad" de Italia. En su oportunidad volveremos sobre este acápite, y señalaremos la inconveniencia de otorgarle efectos retroactivos a la no convalidación; aunque el sistema contrario, que otorga efectos ex-nunc a la no ratificación también tiene sus bemoles.

(f) Otra de las características fundamentales de la legislación de emergencia es la de su transitoriedad. Como el hecho que motiva la medida es uno extraordinario, temporal y grave, una vez solucionada su causa, lógico es que la medida desaparezca. Sostener lo contrario equivaldría a permitir una potestad legislativa del gobierno, incompatible con la división de poderes.

La transitoriedad tiene que ver con la vigencia en el tiempo de la norma. Así, podría ser el propio Ejecutivo el que le asigne determinada temporalidad, o la ley establecer un periodo máximo de vigor. Como podrá apreciarse, la provisionalidad a la que ya hemos hecho referencia también concierne a la vigencia de la norma. Salvo en los regímenes que confieren efecto retroactivo a la no ratificación del Parlamento, en donde se presentan, sin embargo, problemas con respecto a los actos ejecutados durante el período de provisionalidad. En tales regimenes, además, parecería confundirse el propósito de la convalidación, convirtiéndola en requisito de validez del decreto de urgencia. De no ratificarse, entonces, devendría inexistente.

(g) Además del control político, las medidas de urgencia tienen un control jurisdiccional posterior que es ejercido por el órgano que vela por la constitucionalidad de las normas.

(h) Una última caracteristica es la jerarquía de los decretos de urgencia. Hasta donde tenemos conocimiento, dichas medidas extraordinarias tienen rango de ley, aunque se encuentren subordinadas a ratificación posterior del Congreso. Esto es, que 
tanto entre el momento de su emisión y el de su ratificación, así como producida ésta, son leyes en sentido material. El hecho de que el Parlamento -en un plazo que varia según las legislaciones- les confiera eficacia definitiva, nada tiene que hacer con la jerarquía normativa, toda vez que la intervención parlamentaria tiene el objeto de verificar el cumplimiento de los presupuestos habilitantes. Mal podría entonces pensarse que la convalidación otorga a los decretos de urgencia el rango de leyes formales; salvo, claro está, que expresamente sean convertidos en leyes, por medio de una "ley de conversión" como sucede en Italia.

La jerarquía legal de la legislación de emergencia ha sido objeto de controversia en nuestro medio. Sobre todo en el ámbito tributario, que resulta particularmente sensible al empleo del inciso 20. Así, el profesor Humberto Medrano (30) considera que los decretos de urgencia jamás pueden regir supuestos tributarios, esgrimiendo un ortodoxo principio de legalidad como base de su afirmación.

Por el contrario, Armando Zolezzi sostiene que la reserva de ley a que hace referencia el artículo 139 de la Constitución debe interpretarse en el sentido que podrá legislarse en materia tributaria por cualquier norma con rango de ley - sea ésta material o formalen la medida que el principio de legalidad, como referido a la ley dada por el Congreso, tenía razón de ser en las garantías que requería el naciente Estado burgués de los siglos XVIII y XIX.

Siempre en el ámbito tributario, el profesor Hernández Berenguel (31) considera que sólo proceden los decretos de urgencia

(30) MEDRANO CORNEJO, Humberto. Acerca del principio de legalidad en el derecho tributario peruano. En: Revista del Instituto Peruano de Derecho Tributario, № 12, Lima, junio de 1987.

(31) HERNANDEZ BERENGUEL, Luis. El principio de legalidad y las medidas extraordinarias que se pueden dictar mediante Decreto Supremo en materia Económica y Financiera. En: Cuadernos tributarios. № 1, IFA. Lima, octubre de 1986. 
cuando el Congreso se encuentra en receso. Combina su posición el principio clásico de legalidad con la necesidad sobreviniente de legislar sobre materia tributaria cuando el Parlamento no está en funciones.

En la Doctrina española existe también polémica al respecto. Alegre Avila, aunque contrario a la tesis que permite el uso de los decretos-leyes en materia tributaria, ha reseñado los argumentos que a favor de su procedencia se ha esgrimido (32).

En el Perú, la Constitución de 1979 no regula de manera expresa a los decretos supremos de necesidad y urgencia. El inciso 20 del artículo 211 habla de "medidas extraordinarias" que serán dictadas ante urgente necesidad y cuando "así lo requiere el interés nacional". Tal precepto, sin embargo, nos permite colegir que a lo que la Constitución quiso referirse fue a los decretos de urgencia, y así se ha venido interpretando.

Señalemos brevemente los caracteres de la figura contemplada en nuestra Carta Política:

A. Se trata de una facultad del Presidente de la República que no requiere de delegación previa del Congreso;

B. No está sujeto a opinión previa de otro órgano del Estado. La

(32). ALEGRE AVILA, Juan Manuel. La viabilidad constitucional del Decreto-ley en materia tributaria... Op.cit., p. 77. Así, aunque considera tales tesis erradas por ser fruto de un razonamiento de carácter polftico, nos dice que "Por su parte, el profesor PEREZ ROYO... en una línea concurrente con GARCIA DE ENTERRIA y T.R.FERNANDEZ, ha realizado un esfuerzo argumental tendiente a justificar el Decreto-ley en materia tributaria. Sostiene este autor que una vez superada la óptica individualista del principio de reserva de ley tributaria y lejos de la conceptualización del deber de tributar con una visión restrictiva, no hay excesivos inconvenientes en admitir elDecreto-ley en el ámbito tributario, máxime cuandola institución tributaria no afecta el estatuto personal del ciudadano, estando dirigida la intervención del Parlamento a asegurar la publicidad de los debates en una función de composición de intereses". 
adopción de la medida es pues una facultad discrecional del Presidente, pero sujeta a la existencia de los presupuestos habilitantes;

C. Nuestra Constitución contiene muchos vacíos y omisiones que hacen difícil la determinación precisa de la institución:

C.1 Nada se dice acerca de la oportunidad en que el Presidente está habilitado para legislar por esta vía, por lo que podrá hacerlo con prescindencia del funcionamiento del Congreso.

C.2 No se contempla tampoco la necesidad de una posterior ratificación de la medida - es decir, del carácter provisional-. Nuestra Constitución, por el contrario, hace referencia al cargo de dar cuenta al Congreso, lo que se ha interpretado por el Ejecutivo como un simple requisito de informarle sobre las medidas adoptadas. Ello se ha llevado a cabo por medio de oficios en los que se enumera los decretos dictados al amparo del inciso 20 durante un período determinado, sin justificar la necesidad ni la urgencia de las medidas, su carácter económico y financiero, su naturaleza extraordinaria y el interés nacional involucrado.

C.3 La transitoriedad de las medidas extraordinarias es otro de los caracteres que no fluyen del precepto constitucional. Para algunos autores, como María del Rosario Pacheco (33), la transitoriedad se colige de la concordancia del inciso 20 del artículo 211 con el artículo 132 , que dispone que: "En situaciones de crisis grave o de emergencia el Estado puede intervenir la actividad económica con medidas transitorias de carácter extraordinario".

A pesar de que la interpretación anotada permitiría solucionar la omisión hecha a la transitoriedad por el inciso 20, artículo 211, ella nos parece poco apropiada; por cuanto el artículo 132 se refiere a un supuesto de hecho diferente que consiste en una emergencia económica. Esto lo veremos más adelante al analizar el ámbito material de la decretación de urgencia.

(33) PACHECO. Op.cit., p. 53. 
C.4 Finalmente, queda el problema del control jurisdiccional constitucional de las medidas de emergencia; es decir, la posibilidad o no de que sean impugnadas vía acción de inconstitucionalidad de las leyes, lo cual será también materia de posterior análisis.

\subsection{Interpretación de la normatividad vigente: la sana doctrina}

\subsubsection{Hacia la jerarquía legal de los decretos de urgencia}

Tal como están las cosas, queda por dilucidar si los decretos supremos de urgencia tienen o no el rango de ley. En su momento hemos expuesto la posición que les niega tal jerarquía. Toca ahora sustentar la interpretación por la cual tales medidas sí serían leyes en sentido material.

(a) La enumeración de normas con rango de ley en nuestra Constitución no tiene carácter taxativo; toda vez que existen una serie de normas, como es el caso de los convenios y los edictos, que, si bien no son consideradas expresamente como leyes en la Constitución, en la práctica legislativa y jurisdiccional se ha establecido su rango de ley.

Cierto es que la recreación de los edictos en nuestro ordenamiento fue introducida por la Ley de Municipalidades para evitar el control constitucional, puesto que la norma indicada debió ser la ordenanza municipal, pero ello no quita que los edictos tengan jerarquía legal. La intención política que haya tenido el legislador, en definitiva, en nada afecta el rango legal de los edictos.

De similar opinión a la nuestra es Eguiguren (34). Según él, si bien de acuerdo a una interpretación formal de la Constitución los decretos de urgencia no tendrían rango de ley, pues en ésta no existe norma expresa que les reconozca dicha categoría a diferencia de lo que sucede con otras normas; de acuerdo a una

(34) EGUIGUREN. En: Derecho, op.cit., p. 183. 
interpretación sistemática se deduce su carácter de ley material. Por su parte, Zolezzi (35) sostiene que si bien no existe mención expresa de la Constitución, ésta no les niega el rango legal a las medidas extraordinarias.

(b) Del mismo modo, la naturaleza del instituto obliga a que tenga jerarquía legal. De no ser así, ¿cómo podría explicarse el hecho que su aplicación vaya en muchos casos en contra de leyes dictadas por el Congreso? En su momento trataremos el efecto que producen los decretos de emergencia sobre las leyes que afecta, esto es, si las deroga o suspende.

(c) Por el lado del derecho en acción, la reiterada jurisprudencia de la Corte Suprema de Justicia ha establecido el carácter legal de estas normas.

Resulta pertinente transcribir, a título de ejemplo, la Resolución de la Corte Suprema de Justicia del expediente No. 185-88 del 20 de abril de 1988, en los seguidos por Moisés Tambini del Valle con Jaime Alcócer Bonilla sobre desahucio, en donde se establece que "las medidas extraordinarias de naturaleza económica establecidas en los decretos supremos de urgencia que prorrogan el plazo de vigencia de los contratos de arrendamiento, son plenamente compatibles con el interés nacional y guardan armonía con lo dispuesto en el artículo 124 de la propia Constitución (...) que en tal virtud la vigencia de los mencionados decretos supremos no agravia el principio de legalidad contenido en los artículos 87 y 236 de la Constitución Política del Estado (...) que la jurisprudencia establecida (...) hasta la fecha ha sido uniforme en cuanto a sostener la legalidad de los decretos supremos expedidos por el Poder Ejecutivo..." (el subrayado es nuestro).

Recientemente, la Resolución de la Corte Suprema del 18 de enero de 1990, publicada en el Boletín de la Academia de la Magistratura, estableció la improcedencia de una demanda de desahucio por considerar "que los decretos supremos (de

(35) ZOLEZZI: Op.cit., p. 28. 
urgencia) tienen rango de ley. Merecen respeto las normas por la naturaleza de su contenido y de su procedencia, no existiendo violación del principio de jerarquía de leyes por su carácter temporal". (el subrayado es nuestro).

(d) De no tener carácter legal, asimismo, resultaría poco técnico y hasta redundante que el Constituyente de 1978 haya establecido en dos acápites diferentes del artículo 211 -el 11 y el 20- una facultad legislativa similar para el Presidente de la República. De no ser así, ¿qué sentido tendría entonces no haber incluido a las "medidas extraordinarias" a que hace referencia el inciso 20 dentro de los habituales decretos supremos del inciso 11 ?

Todo ello se ve corroborado por la circunstancia que el Decreto Legislativo 560 - Nueva Ley del Poder Ejecutivo- regula expresamente la facultad conferida al primer mandatario por el inciso 11, y en ningún momento hace mención de la posibilidad de que aquél pueda dictar medidas extraordinarias.

Ello permitiría inferir que no estamos ante un simple decreto supremo. La razón de su extraordinariedad está dada, precisamente, por su mayor jerarquía, además de tener requisitos de validez distintos. Además, el decreto supremo ordinario puede necesitar aprobación del Consejo de Ministros, en cambio los decretos de urgencia emanan de potestad exclusiva del Presidente.

(e) Como señala Zolezzi (36), al haber dispuesto nuestra Constitución para los decretos de urgencia el requisito de dar cuenta al Congreso, "se les da el mismo trato que a los decretos legislativos, y ello sólo tiene sentido en la medida que se ha incursionado en atribuciones que normalmente son competencia del Congreso, lo que ratifica la vocación de ley de los decretos de urgencia". (...) "No debe olvidarse, además, que estas medidas extraordinarias normalmente son contra legem, o sobre materia que en condiciones normales deben ser reguladas por ley formal; por lo que, para regir, requieren de una potencia o fuerza igual que la ley".

(36) ZOLEZZI. Ibidem. 
(f) El argumento de la interpretación histórica que reseñáramos líneas arriba - por el que la Asamblea Constituyente rechazara el proyecto de conferirle rango de ley a las medidas de urgenciano enerva necesariamente lo hasta aqui dicho. Como sabemos, la norma una vez que entra en vigencia cobra virtualidad jurídica propia, por lo que su interpretación no puede verse constreñida a lo que quiso el legislador. La interpretación auténtica es sólo potestad del Congreso.

En este sentido, es válida la afirmación según la cual el artículo 298 inciso 1 -que regula la acción de inconstitucionalidadtiene carácter enunciativo. De esa manera debe incluirse dentro de su ámbito de aplicación a los decretos supremos de urgencia, así como a los edictos y a toda otra norma con rango de ley material que se cree en el futuro.

En consecuencia, pensamos que una correcta interpretación de la naturaleza de los decretos presidenciales de urgencia nos debe llevar a la conclusión de su rango o fuerza de ley (37). De no ser así, llegaríamos al absurdo de quienes sostienen la existencia de un instituto que en muy poco se condice con su esencia; permitiendo, por tanto, la existencia de un híbrido.

En efecto, si no consideramos que estas normas tienen rango legal, no podrían tratar materia reservada a ley, lo que les haría carecer de sentido. Recuérdese precisamente que su finalidad es dar inmediata solución a una urgencia coyuntural.

(37) A esta misma conclusión han arribado Carlos CARDENAS QUIROS, Manuel DE LA PUENTE Y LAVALLE, Francisco EGUIGUREN PRAELI, Domingo GARCIA BELAUNDE, César LANDA ARROYO, Humberto MEDRANO CORNEJO (aunque postula la no procedencia del inciso 20, numeral 211 para cuestiones tributarias), Alfredo QUISPE CORREA y Armando ZOLEZZI MOLLER. Enrique BERNALES BALLESTEROS y Marcial RUBIO CORREA en la última edición de su trabajo colectivo sobre la Constitución, han cambiado de parecer. Luis HERNANDEZ BERENGUEL también opina a favor del rango legal de las medidas extraordinarias del 211 , inciso 20 , aunque condiciona su procedencia al receso parlamentario. Le niegan el rango legal Enrique CHIRINOS SOTO y Piedad PAREJA PFLUCKER. 


\section{PROBLEMATICA ESPECIFICA EN TORNO A LOS DECRETOS DE URGENCLA}

\subsection{Qué debemos entender por "medidas extraordinarias"}

Después de haber analizado el rango de los decretos de urgencia, podemos concluir que nuestra Constitución ha establecido un tipo de norma distinto a los decretos supremos ordinarios, que goza de rango legal.

Por "medidas extraordinarias" debemos entender, entonces, que estamos ante un tipo de norma legal en sentido material. De igual manera, tal norma especial surge como respuesta a circunstancias súbitas, imprevisibles y urgentes que puedan afectar la seguridad y el patrimonio de los ciudadanos. En tal sentido, sólo una actuación rápida podría brindar solución efectiva, lo que no se lograría de acudirse al procedimiento legislativo ordinario.

De otro lado, por medidas puede entenderse no sólo normas, sino toda decisión tomada para conjurar una situación de grave emergencia. Ello no obstante, en el ámbito que nos interesa, tales decisiones no estarían sujetas a ningún condicionamiento, puesto que éste será necesario solamente en las decisiones que se traduzcan normativamente.

\subsection{En torno a la urgencia}

Toca ahora pronunciarnos respecto a qué debe entenderse por urgencia. El concepto de urgencia subyace a las medidas que contempla el inciso 20 del numeral 211 de la Constitución, así como en todas las figuras similares recogidas en el Derecho Comparado.

Si bien la urgencia es un concepto legalmente indeterminado, ello no supone en el Ejecutivo una facultad discrecional para señalar en cada caso si existe o no urgencia. Como sostiene el español Salas (38), "Lo peculiar del concepto indeterminado es la unidad de solución justa en la aplicación del mismo a una circunstancia concreta, frente

(38) SALAS, Javier. Op.cit., p. 67 (nota a pie de página). 
a lo que es propio de las facultades discrecionales, la pluralidad de soluciones justas posibles. Hay que hacer del concepto indeterminado uno determinado, pero esto no es ejercicio de la potestad discrecional, sino interpretación".

Clavero Arévalo (39) afirma que "una situación es urgente si el factor de tiempo es elemento determinante y constitutivo del fin perseguido"; lo que, como resultará evidente, es lo que ocurre cuando debe recurrirse a esta facultad legislativa extraordinaria, por ser ineficaz el procedimiento ordinario de dación de leyes. Así, la urgencia constituye uno de los supuestos de la necesidad, cual es la de obrar rápidamente, sin dilación de tiempo una materia que, en situaciones regulares, debiera serlo por ley formal.

No debe entenderse, sin embargo, que la urgencia equivalga a circunstancias excepcionales. "Para que se dé la urgencia, no es preciso que se haya producido una alteración del orden público, ni una crisis política, ni una calamidad social. Puede producirse la urgencia en circunstancias perfectamente normales" (40). En consecuencia, los decretos de urgencia son perfectamente procedentes en circunstancias de paz social y orden público.

En igual sentido se ha pronunciado el Tribunal Constitucional español, para el que la extraordinaria y urgente necesidad no debe entenderse en el sentido extremo de una amenaza para la nación o para el sistema constitucional, pues para estos supuestos existe el régimen de excepción (41).

El que la determinación de la urgencia no dependa exclusivamente de la discrecionalidad del Presidente, no quita que su valoración admita criterios políticos. Sin embargo, extraordinariedad y urgencia no son puros postulados políticos, ni son tampoco supuestos de apreciación gubernativa discrecional —como señala Astarloa (42)-,

(39) Citado por SALAS. Ibid. p. 68.

(40) Ibid., p. 70.

(41) Boletin de jurisprudencia constitucional, op.cit.

(42) A.STARLOA. Op.cit., pp. 118-119. 
sino "conceptos jurídicos indeterminados, a determinar caso por caso por medios jurídicos, partiendo de la importante construcción dogmática levantada a tal efecto por la doctrina... (...). Por lo demás, la valoración del presupuesto habilitante no puede ceñirse a la apreciación de las circunstancias de hecho. Exige también constatar que las medidas adoptadas se adecúan en el caso concreto y de forma estricta a las necesidades afrontadas". En España se ha hablado de "conexión de sentido entre la situación definida y las medidas que en el decreto se adoptan".

En consecuencia, de no mediar esta conexión existiría una "insuficiencia originaria de habilitación"; por lo que el decreto podría ser atacado en su constitucionalidad si el Congreso lo ratifica, o éste negarle su ratificación.

Podria decirse, entonces, que si bien estamos frente a una potestad exclusiva del Presidente y hasta discrecional en su adopción, esta discrecionalidad se encuentra sujeta a que se den los presupuestos habilitantes; por lo que, presentes estos, el Presidente tendrá la discrecionalidad de tomar la medida o no.

Esto que en teoría corresponde a la naturaleza del instituto que analizamos, no quita que en la práctica se haya prostituido la observancia al requisito de la urgencia; lo que se ha traducido en una utilización abusiva de las "leyes de gobierno". Pero aceptar lo dicho permite que, probado el exceso presidencial, la medida pueda ser impugnada. La carga de la prueba corresponderá, eso sí, al recurrente.

La situación se muestra más grave aún porque, salvo contadísimas excepciones, jamás se ha motivado la necesidad ni la urgencia a la hora de dictar un decreto excepcional. Aunque, como es obvio, la mera motivación tampoco supone el cumplimiento del requisito.

\subsection{El alcance de la "materia económico-financiera"}

Un problema adicional aparece al querer interpretar a qué ha querido referirse el Constituyente por "materia económica y 
financiera". Señalemos, previamente, que nuestra Constitución establece un límite material poco frecuente a la aplicación de la decretación de urgencia, que suele estar abierta a toda la reserva de ley.

Hace un momento, cuando hablamos de la posición de Pacheco, vimos la posibilidad de concordar el artículo 211 inciso 20 con el artículo 132.

Dicho numeral dispone que "en situaciones de crisis grave o de emergencia el Estado puede intervenir la actividad económica con medidas transitorias de carácter extraordinario". Este precepto, sin embargo, apunta a un supuesto de hecho diferente. En primer término, el artículo 132 está ubicado en el Título del Régimen Económico, Capítulo Cuarto - De la Empresa.

Para el constitucionalista Francisco Eguiguren (43), este precepto corresponde a una legislación de situaciones de emergencia, conocida en doctrina como emergencia económica. El mismo autor considera que este artículo está mal ubicado dentro de la Constitución, pues debió estarlo en el capítulo referido a los principios económicos, como sucede en España, en donde estas medidas están circunscritas expresamente a la intervención de una empresa en casos de emergencia, o cuando peligra todo un sector de la actividad productiva.

Se ha sostenido que el supuesto del numeral 132 forma parte de la potestad presidencial de emitir decretos de urgencia. Así, Pacheco considera que, incluso, la mención expresa a la transitoriedad de las medidas extraordinarias se encuentra en este artículo constitucional (44).

En opinión nuestra, nos encontramos ante dos medidas o

(43) vid. EGUIGUREN PRAELI, Francisco.Los retos... Op.cit., pp. 227-229. El autor señala que el artículo 132 de la Constitución peruana "resulta emparentado con la figura de la 'emergencia económica' (bastante regulada en la experiencia colombiana) que aparece como complemento de los regímenes de excepción o emergencia por razones políticas y sociales (similares a lo previsto en el artículo 231 de nuestra Carta)".

(44) PACHECO. Op.cit., p. 53. 
normas que son facultad gubernativa pero que tienen un campo material de aplicación diverso. Efectivamente, el artículo 132 haría referencia al ámbito de la actividad económica; y permitiría dejar en suspenso determinados derechos constitucionales, como la iniciativa privada, por ejemplo, o hacer posible el control de precios, cosa que a la fecha se ha venido haciendo por el inciso 20, artículo 211. Esta intervención del Estado podría orientarse tanto a niveles micro como macroeconómicos, aunque según Eguiguren, la norma estuvo pensada en términos macro (45).

Así, el mismo autor señala que "el artículo 132 desarrolla y perfecciona atribuciones parecidas a las contenidas en los artículos 40 y 49 de la Constitución peruana de 1933, que ante situaciones de crisis, emergencia o necesidad autorizaba disponer limitaciones en la libertad de comercio e industria para preservar el abastecimiento y los precios de los alimentos y subsistencias para la población. Se puede inferir que este precepto autoriza al Estado a disponer y realizar una intervención temporal en el desenvolvimiento de las actividades económicas, productivas y de servicios, a fin de garantizar el normal funcionamiento de las relaciones en el marco de una economía social de mercado y la satisfacción de las necesidades fundamentales de las personas, así como de corregir distorsiones o situaciones de crisis creadas por efecto de desabastecimiento, incremento excesivo de precios, prácticas monopólicas, especulación, colapso de algún sector de la actividad económica, etc." (46).

En cambio, el artículo 211 inciso 20 posee un ámbito de aplicación restringido, cual es la materia económica y financiera.

Para saber a qué ámbito nos referimos, debemos concordar el 211 inciso 20 con el artículo 138, de tal forma que por materia económica y financiera debemos entender todo lo relativo al manejo de la Hacienda Pública. Es el caso de los empréstitos y las modificaciones a las leyes de presupuesto, siempre, claro está, que así lo requiera el interés nacional. Asimismo, comprende el área de lo

(45) EGUIGUREN. Notas del curso de Temas de Derecho Constitucional I, segundo semestre de 1989.

(46). EGUIGUREN. Los retos... Op.cit., p. 228. 
tributario, lo aduanero y lo crediticio, siempre que se presente el supuesto de la urgente necesidad que habilite la dación de los decretos de emergencia.

Existen otras diferencias entre ambos preceptos constitucionales. Así, el inciso 20 del artículo 211 trata de una facultad exclusiva del Presidente; mientras que el numeral 132, en tanto atribución del Estado, podría ejecutarse mediante decreto del Ejecutivo como por ley del Congreso (47).

Ya hemos analizado la polémica existente entre los tributaristas con relación a la procedencia o no de la legislación de emergencia para regular materia tributaria, en función de una interpretación clásica o una moderna del principio de legalidad. No es éste el lugar de repetir la controversia, aunque, como resultará evidente, adscribimos a la interpretación de Zolezzi, según la cual el principio de legalidad se refiere hoy a toda norma con rango o fuerza de ley.

La concepción clásica del principio de legalidad respondía a los requerimientos de la emergente clase burguesa de poder controlar la creación de tributos. Hoy en día, tal supuesto histórico ha quedado superado y, además, la normatividad tributaria requiere de niveles de especialización difícilmente presentes entre los representantes parlamentarios.

Se acepte o no la interpretación amplia del principio de legalidad consagrado en el numeral 139 de la Constitución Política, ante una situación de urgente gravedad y cuando así lo requiera el interés nacional, podría legislarse vía decreto de urgencia supuestos tributarios, inclusive la creación de nuevos tributos, aunque éstos serían necesariamente temporales (al igual que el propio decreto).

\subsubsection{Cuando el continente no se ajusta al contenido: 1640 decretos de urgencia en 9 años}

Según la investigación que realizara el despacho del

(47) Ibid., p. 227. 
senador Enrique Bernales, a la que hiciéramos mención, hasta julio de 1989 el gobierno central había emitido 1640 decretos supremos de emergencia.

La gran mayoría de estas medidas se refieren a áreas que exceden el ámbito de aplicación a que el inciso 20 se contrae. Desde modificaciones al régimen laboral hasta aspectos remunerativos, desde problemas de vivienda hasta a prórrogas a los contratos de arrendamiento, desde modificaciones tributarias hasta la creación de beneficios tributarios, desde la declaratoria de estados de emergencia por razones de seguridad hasta la declaratoria de emergencia en diversas actividades económicas, desde la recategorización de plazas artísticas en la Orquesta Sinfónica hasta lo insólito: la aprobación del Reglamento del juego de bingo, los decretos presidenciales han constituido el "cofre de pirata" por el que se ha legislado sobre cualquier asunto. En realidad, a este respecto el cielo ha sido el límite a la imaginación de nuestros gobernantes.

Obviamente, todo lo anteriormente expuesto ha contribuido a la desnaturalización del instituto, que prácticamente ha sido prostituido en sus diez años de vigencia. Nada de lo comentado hubiese sido posible, además, de no haber contado los gobiernos de Acción Popular y del APRA con mayoría en el Congreso.

\subsection{Vigencia de los decretos supremos de urgencia y necesidad}

Otro problema que surge de la institución tal como está tratada en el Perú, es el relativo a la vigencia que deben tener los decretos presidenciales de urgencia. Cuando analizamos sus caracteres, vimos que uno de ellos era la transitoriedad; esto es, que una vez solucionado el motivo que les dio origen, el decreto debe expirar.

Nuestra Constitución no se pronuncia sobre este punto; sin embargo, de la esencia del instituto fluye que deben necesariamente estar sujetos a plazo. De opinarse de manera distinta, llegaríamos al absurdo de aceptar un instrumento legislativo con vocación de permanencia, lo que no se condice con las situaciones extraordinarias que son su causa. 
La transitoriedad o temporalidad de la medida, no obstante, no podría tener en todos los casos un mismo plazo de vigencia. Este dependerá de cada circunstancia, y debería estar consignado en los considerandos de la norma. Como sabemos, el presupuesto de hecho habilitante - según Antonio Torres del Morral (48)- es la excepcional y urgente necesidad que requiere ser solucionada. Dicha necesidad puede requerir, pues, de un tiempo mayor o menor para ponerle coto.

Como el vigor de los decretos de urgencia no puede ser unívoco, se desprende con mayor razón la exigencia de un control parlamentario posterior - la provisionalidad, como veremos luegoque implique la ratificación de la medida, y no la simple comunicación al Parlamento, como se ha venido interpretando por "dar cuenta al Congreso".

Una alternativa válida sería el otorgarle legislativamente un plazo de vigencia máximo. Como la circunstancia de emergencia es algo indeterminado, cuya apreciación depende de la discrecionalidad política del Presidente, una manera de evitar posibles arbitrariedades, sobre todo con mayoría parlamentaria, es mediante un plazo máximo de vigencia. De esta manera, la decisión política podrá jugar dentro de dicho plazo.

De transcurrir éste y continuar la emergencia, podrá el Poder Legislativo renovar la vigencia de la medida, o, en todo caso, podría el Ejecutivo dictar otro decreto.

El primer borrador del Anteproyecto de Ley de Democratización de las Decisiones de Gobierno, elaborado por el Instituto Libertad y Democracia (ILD) y publicado en el diario oficial El Peruano el 28 de febrero de 1990, presenta un similar parecer. Así, su artículo 88 establece que "(...) Sin necesidad de que así lo establezcan, tienen una vigencia máxima de seis meses prorrogables si subsisten las causales que determinaron su vigencia y si el Congreso no les confiere formalmente fuerza de ley".

(48) TORRES DEL MORRAL, Antonio. Principio de derecho constitucional español. Atomo ediciones. Madrid 1986. 
Por consiguiente, si el Congreso convierte a los decretos en leyes formales, tendrían éstos la misma vigencia que las leyes; esto es, que sólo podrían interrumpirse en sus efectos por derogación expresa o tácita.

Debemos mencionar, de otra parte, que los decretos de urgencia rigen desde el día siguiente de su promulgación, como sucede, salvo indicación distinta, con los decretos supremos ordinarios.

Cuando indicamos los caracteres de la legislación de emergencia en la legislación comparada, mencionamos el doble efecto de la provisionalidad. Vimos que ésta no solamente operaba respecto de la eficacia del decreto, sino también sobre su vigencia. Y resulta lógico que así sea. Si la eficacia de la norma es provisional hasta la ratificación parlamentaria y si ésta se manifiesta en contra, la vigencia del decreto habrá sido también provisional —no sólo su eficaciahasta la denegatoria de confianza expresada por el Congreso. Como podrá apreciarse, la provisionalidad en la vigencia es el correlato o reflejo de la eficacia provisional.

También señalamos que el efecto de la provisionalidad sobre la vigencia no se presentaba en los regímenes que, como el italiano, otorgan efectos retroactivos a la no ratificación. Hemos considerado la retroactividad un error, pues equivaldría a considerar a la ratificación parlamentaria como requisito de validez.

En último término, resulta oportuno resaltar la opinión de Zolezzi con respecto a la vigencia de los decretos de urgencia en el ámbito tributario. A falta de plazo y en la medida que en el campo impositivo las normas tienen vigencia anual (año fiscal), dichos decretos deberían adecuarse al calendario fiscal (49).

4.5 Provisionalidad de los decretos supremos de urgencia y la necesidad de un control parlamentario posterior

Un tema de especial interés es el relativo al carácter provisional de los decretos de urgencia. Por provisionalidad debemos

(49) ZOLEZZI, Op.cit. 
entender la eficacia relativa de tales actos de gobierno, es decir, condicionada a convalidación parlamentaria. Así, su eficacia definitiva dependerá de la posterior ratificación del Congreso. Esto no significa, sin embargo, que el decreto, de ser ratificado, rija desde la fecha de ratificación, sino que ésta se retrotrae a la fecha de emisión. En consecuencia, el pronunciamiento parlamentario positivo tiene efecto declarativo.

La convalidación parlamentaria, de otro lado, no supone la conversión en ley formal del decreto, sino solamente su transformación de provisional en definitivo; en consecuencia, no implica cambio alguno en su naturaleza jurídica, por lo que se mantiene como ley material. Salvo, claro está, que el Congreso decida darle permanencia mediante ley expresa.

En el Perú, la Constitución establece la necesidad de dar cuenta al Congreso, sin señalar cuál es la sanción si la norma no es presentada, ni tampoco cuál es el plazo en que la presentación deberá verificarse. Más grave aún, el texto constitucional no define en qué consiste el "dar cuenta", por lo que se ha interpretado que tal requisito se satisface con la mera comunicación.

Tal práctica desnaturaliza por completo el instituto, a la vez que permite la duda respecto de su rango legal. Ello no obstante, el Colegio de Abogados de Lima ha avalado, mediante Oficio No. 019-86-88, la, a nuestro juicio, incorrecta práctica. De opinión similar a la del CAL es el Anteproyecto del ILD.

Con el respeto que merecen las instituciones aludidas, somos de la opinión que por "dar cuenta al Congreso" la norma supone algo más que un simple informe sobre las normas dictadas al amparo del inciso 20 . Creemos, más bien, que hace referencia a la provisionalidad como característica esencial de las medidas extraordinarias.

Una de las funciones principales del Parlamento es la fiscalización del Poder Ejecutivo. En el caso especifico de las medidas de emergencia, la función fiscalizadora del Congreso debe expresarse en la capacidad de revisar si su emisión satisface las condiciones y requisitos que deben llenar, por lo que podría pronunciarse por su aprobación o descalificación. Más aún cuando en nuestro sistema 
constitucional el titular de la potestad legislativa es el Parlamento, lo que impide al gobierno dictar directamente en situaciones normales disposiciones con fuerza de ley. Precisamente, la convalidación parlamentaria es no sólo la que les da eficacia definitiva a los decretos de urgencia, sino la que justifica en términos de control su jerarquía legal. Astarloa (50), refiriéndose al control parlamentario, llega a decir que es "un complemento lógico y consustancial con el uso de la decretación de urgencia".

Somos conscientes, sin embargo, de que la vaguedad de la expresión "con cargo de dar cuenta al Congreso" permite ésta como otras interpretaciones. Podría afirmarse, sin embargo, que la expresión "dar cuenta" es una que, en el uso peruano del lenguaje, siempre ha supuesto una relación de jerarquía entre quien rinde la cuenta y quien la recibe. Incluso este último tiene la facultad de aprobarla o no, lo que abonaría aún más la tesis que la provisionalidad sí está contemplada en el inciso 20 del numeral 211 de la Constitución.

Consideramos, entonces, que nuestra opinión es la que responde a la naturaleza del instituto, por lo que se debería dictar una ley interpretativa o una modificatoria del Reglamento del Congreso que posibilite el establecimiento de un control parlamentario de los decretos de urgencia. Otra salida estaría por el lado del funcionamiento parlamentario, que asuma una posición más activa con respecto de este tema. Indicios de esta conducta se han podido apreciar durante el pedido de censura al Ministro de trabajo del gobierno actual, doctor Carlos Torres y Torres Lara; aunque, salvo contadísimas excepciones, nuestros representantes demostraron sin pudor alguno su total ignorancia por el asunto que los convocaba. manera:

La provisionalidad, de otro lado, funciona de la siguiente

- CONGRESO ENFUNCIONES. Emitido y publicado en el diario oficial, el decreto de urgencia deberá ser presentado al Congreso para su convalidación o no dentro del término que se establezca. Un primer punto es analizar si la revisión la realiza una sola cámara -como sucede, por ejemplo, en España con el Congreso

(50) ASTARLOA. Op.cit., p. 138. 
de Diputados- o el Congreso en pleno. Una interpretación literal del artículo 211, inciso 20, parecería exigir el control de ambas cámaras; lo que se vería confirmado si la sistematizamos con lo prescrito en el artículo 186 inciso 2, que habla de la atribución del Congreso de velar por el respeto de la Constitución. Esto podría acarrear, sin embargo, problemas de operatividad.

Creemos, por tanto, que más práctico resultaría la revisión por una sola de las cámaras, específicamente por la de diputados, como cámara política, toda vez que el inciso 20 podría ser interpretado como que utiliza el concepto Congreso en términos coloquiales; y que la atribución de velar por la constitucionalidad del ordenamiento jurídico si está en el Congreso, obviamente también en cada una de sus cámaras.

Otros, sin embargo, consideran que más que una cámara, debería ser la Comisión Bicameral de Presupuesto la que someta al control ulterior a la decretación de urgencia (51). Consideramos que ésta es una vía perfectamente posible, toda vez que esta comisión se encarga, precisamente, de estudiar las materias que son el ámbito de regulación del 211 inciso 20.

Cualquiera sea el sentido de la revisión parlamentaria, ésta deberá ser publicada en el diario oficial.

- RECESO PARLAMENTARIO. En caso de receso parlamentario, la norma deberá ser presentada ante la Comisión Permanente del Congreso, la que estará facultada a ejercer la revisión. Si esto es así, nada impediría que una sola Cámara sea la encargada del control.

- DECRETO RATIFICADO. Ya vimos que adquiere eficacia definitiva. Ahora bien, si el decreto convalidado fuere inconstitucional, el hecho de la ratificación no implica su inatacabilidad. La posibilidad de su impugnación deberá mantenerse, incluso una vez expirado el decreto por vencimiento del plazo de vigencia; aunque debería establecerse un término pres-

(51) En este sentido, EGUIGUREN, Los retos... Op.cit., p. 237. 
criptorio reducido de los recursos impugnatorios, toda vez que estamos frente a medidas temporales.

Resulta pertinente el comentario de Astarloa (52), en el sentido que la voz "convalidado" parecería hacer alusión a que producido el pronunciamiento favorable del Congreso, la norma quedaría sanada de sus eventuales vicios. Sin embargo, esto no es así, por lo que, si se quiere, más apropiado es hablar de ratificación $u$ homologación.

- DECRETO NO RATIFICADO. Si la norma es presentada al Parlamento y éste no la convalida - por considerar que no se ajusta a sus requisitos técnicos, o por razones de oportunidad política- se entiende que caduca, esto es, que deja de existir. La caducidad supone que la norma perderá sus efectos desde el momento en que opera, lo que implica que sus efectos sean extunc.

De opinión contraria, sin embargo, es la Constitución italiana, pues establece en el artículo 77 que "(...) Los decretos pierden eficacia desde el principio si no se convierten en ley dentro de los 60 días de su publicación". En consecuencia, la Carta italiana le da efectos ex-tunc o retroactivos a la no ratificación.

Como hemos señalado, consideramos esta solución errada, puesto que la provisionalidad es precisamente un requisito de eficacia y no de validez; por lo que la norma rige provisionalmente hasta su convalidación o caducidad, a partir de donde, si es convalidada, tendrá una eficacia definitiva. Dicha convalidación, asimismo, le ratifica el rango legislativo desde un inicio.

La afirmación según la cual la no convalidación tiene efectos hacia adelante - no retroactivos- tiene una manifestación práctica evidente: la no afectación de las relaciones jurídicas realizadas al amparo de la norma emitida por el Ejecutivo entre

(52) ASTARLOA. Op.cit., p. 156. El autor habla de que la palabra "convalidación" parecería insinuar "un cierto valor terapéutico y al tiempo parece presuponer la existencia de vicio en todo Decreto-Ley..." 
el momento de su promulgación y el de su pase al Congreso. Debe tenerse presente que el objetivo de la legislación de emergencia es regular de manera inmediata una grave y urgente necesidad, objetivo que podría verse entorpecido por una situación de incertidumbre. Del mismo modo, ya se ha señalado que para opinión de este trabajo, la ratificación del Congreso no supone requisito alguno de validez.

Por no considerar el sistema italiano lo antes expuesto, es que de no ser convalidada en él la medida dentro de los 60 días de su presentación al Congreso, éste podrá legislar sobre los derechos surgidos durante el período de "vigencia". Esto es, sobre los derechos surgidos durante la etapa de incertidumbre.

Ello no obstante, los efectos ex-nunc (hacia adelante) de la no convalidación deja abierta la posibilidad a un uso incontrolado de los decretos de urgencia. En efecto, al haber regido y generado relaciones jurídicas durante su eficacia provisional, un eventual vicio en la dación del decreto se veria indirectamente subsanado, al ser dichas relaciones inatacables. Para evitar esta situación, sería conveniente que se estableciera algún mecanismo que evite la inatacabilidad de los actos realizados en ejecución del decreto; así como el corte de los recursos de inconstitucionalidad.

- SILENCIO DEL CONGRESO. Si el Congreso guarda silencio una vez presentada la norma a su consideración, esto es, si dentro del plazo que se establezca para su pronunciamiento no lo hiciera, debe entenderse que el decreto no es convalidado, puesto que la convalidación ha de ser expresa. Lo contrario sería admitir que el silencio del Congreso es suficiente para ratificar excepciones a su potestad legislativa. No puede hablarse, en este sentido, de "ratificación tácita"; si se quiere, estamos ante una tácita caducidad.

- RATIFICACION A POSTERIORI. Tampoco sería procedente la "convalidación a posteriori"; esto es, que vencido el plazo para su pronunciamiento, el Congreso decida llevarlo a cabo extemporáneamente, "dado que no estamos ante un nuevo diálogo entre órganos constitucionales, sino ante garantías 
establecidas para la defensa del ciudadano" (53). En tal supuesto el decreto ya habría caducado.

- DECRETO NO PRESENTADO. Por último, si el Ejecutivo no presentare el decreto para la revisión y aprobación parlamentaria, éste caducaría al igual que si no se hubiere aprobado la revisión. Ello sin perjuicio de la sanción política que corresponda al ministro o ministros responsables. Para otros (54), como intención sancionadora, la ineficacia debería tener efectos ex tunc; sanción que se desprende del artículo 186 inciso 2 , in fine.

- DEROGATORIA DEL DECRETO. Algunos estudiosos hablan de derogatoria en lugar de caducidad. Resulta oportuno determinar que la derogatoria de un decreto de urgencia sólo podría proceder cuando éste ha sido previamente ratificado, por lo que pese a contar con eficacia y vigencia definitivas, el Parlamento o el propio Ejecutivo deciden hacerlo cesar en sus efectos mediante norma expresa. La caducidad, a su turno, se refiere al efecto que sobre el decreto de urgencia produce la no ratificación del Congreso o el paso del plazo de su vigencia, cuando fue previamente ratificado. Como podrá apreciarse, la derogatoria nada tiene que ver con la provisionalidad.

4.6 Efectos sobre la normatividad preexistente: ¿derogación o suspensión?

Un problema particularmente grave que produce la parquedad del tratamiento constitucional a los decretos de urgencia, es el que se refiere a sus efectos sobre la normatividad preexistente.

(53) ASTARLOA. Op.cit., p. 145.

(54) Así, PACHECO considera que en dicho supuesto "... la sanción debe ser más severa: la pérdida de los efectos desde el momento mismo en que entró en vigor, es decir, con efectos ex nunc (sic); pero quedando a cargo del Congreso la obligación de dar una ley en el plazo perentorio que la ley reguladora de los decretos de urgencia establecerá, destinada a reglamentar la materia que trató el decreto que perdió vigencia". Op.cit., p. 54. 
La práctica en el uso de tales medidas ha hecho que en innúmeros casos éstas hayan modificado normas legales anteriores. Como ya vimos, de la esencia de las medidas extraordinarias fluye su rango legislativo y su transitoriedad. Ahora bien, si son medidas sujetas a plazo, ¿pueden derogar leyes preexistentes o sólo las dejan en suspenso?

El artículo I del Título Preliminar del Código Civil de 1984 prescribe que "La ley se deroga sólo por otra ley. (...) Por la derogación de una ley no recobran vigencia las que ella hubiera derogado".

Nuestra Constitución ha onpitido hacer precisiones a este respecto. En su sistemática, asimismo, no se establece la suspensión normativa. Tal circunstancia ha hecho que varios analistas se hayan pronunciado a favor de los efectos derogatorios de las medidas de emergencia; y que otros - como De la Puente (55) — hayan buscado una salida al hablar de una "modificatoria temporal".

Discrepamos frontalmente del efecto derogatorio. Si los decretos de urgencia son transitorios y están sujetos a una emergencia pasajera, mal podrían derogar normas permanentes emitidas en razón de circunstancias habituales. Precisamente, la facultad legislativa del inciso 20 responde a dar pronta solución a un hecho coyuntural, por lo que resulta contradictorio pensar que una medida de coyuntura pueda derogar a una con vocación de permanencia.

Si no fuera esto así, superada la emergencia nos encontraríamos ante un vacio legal, que requeriría ser cubierto por la dación de una ley exactamente igual que la supuestamente derogada. Todo un despropósito.

Un argumento adicional lo tenemos en la propia naturaleza de la vigencia de los decretos extraordinarios. En rigor, una vez vencido su plazo no se derogan, sino caducan. De esto se sigue que cuando modifican o contravienen normas legales, no es que éstas últimas queden derogadas, sino que sus efectos quedan suspendidos

(55) DE LA PUENTE Y LAVALLE, Manuel. Las medidas extraordinarias. En: Revista Peruana del Derecho de la Empresa. № 20 1986, pp. 77-85. 
en tanto dure la emergencia que el decreto contempla; por lo que, caduco éste, recuperan plena eficacia.

La subsistencia del problema está, como se dijo, en que la Constitución no ha establecido la figura de la suspensión de las leyes. Esta omisión podría ser resuelta, sin embargo, mediante interpretación auténtica del Congreso del inciso 20 del numeral 211 de la Constitución.

4.7 El control jurisdiccional constitucional: apuntes para su procedencia en las medidas extraordinarias

La Constitución de 1979, a diferencia de la de 1933, ha establecido un sistema mixto de control de la constitucionalidad de las normas.

Así, prescribe un control concentrado ad-hoc de la constitucionalidad, de justicia constitucional, o también denominado sistema europeo, con el Tribunal de Garantías Constitucionales(TGC), creado expresamente para este fin; con facultades para declarar, con efectos erga omnes, la inconstitucionalidad parcial o total de leyes, decretos legislativos, normas regionales de carácter general y ordenanzas municipales.

Simultáneamente, nuestra Constitución establece un control difuso de la constitucionalidad de las normas, conocido como el judicial review o sistema americano, que brinda la posibilidad que sea el propio órgano jurisdiccional -léase Poder Judicial- el que revise la constitucionalidad de las leyes y demás normas, inaplicándolas para el caso concreto; es decir, una declaración de inconstitucionalidad inter partes. Ello no obstante, la Ley Procesal de Acción Popular (Ley 24968) le da efectos erga omnes a sus resoluciones, por lo que, al darle efectos derogatorios de la norma inconstitucional a sus fallos, mezcla características del control difuso con el concentrado.

El artículo 298 inciso 1 de la Constitución establece el control concentrado. El problema que se deriva de esta norma - al que ya hemos hecho referencia- es el de establecer si contiene una 
enumeración taxativa o una simplemente enunciativa de las normas susceptibles de ser impugnadas vía acción de inconstitucionalidad.

Hemos visto en su momento el caso de los edictos. Al igual que ellos, los decretos supremos de urgencia son normas con rango legal. No vamos a tratar aquí la posibilidad de atacar los efectos de los decretos de urgencia vía acción de amparo, pues esta vía está expedita de producirse la conculcación de un derecho constitucional por medio de un acto derivado de la aplicación del decreto. Esto atañe, sin embargo, al control difuso, cuyos efectos son la inaplicación para el caso concreto.

Nos interesa sí dilucidar la posible impugnación de las medidas extraordinarias vía acción de inconstitucionalidad. De aceptar la jerarquía legal de tales normas, resulta lógica consecuencia el considerar a la enumeración del artículo 298 inciso 1 como enunciativa; pues de lo contrario, estaríamos ante el caso de una norma legal inatacable, que dejaría desprotegidos a los eventuales afectados, siempre y cuando, claro está, dicha afectación resulte inconstitucional por no cumplir la medida con sus requisitos de validez. Tal hipótesis aparece como incompatible con los principios que inspiran nuestra dogmática constitucional (56).

En sintesis, debemos considerar, para guardar la armonía del sistema y en salvaguarda de la seguridad jurídica, que el inciso primero del numeral 298 de la Carta Magna es aplicable a toda norma con rango de ley. Dicha interpretación extensiva de la norma es válida, puesto que una vez emitida ésta cobra virtualidad jurídica propia. Sería muy valioso, a este respecto, un pronunciamiento ex-

(56) Con respecto a la procedencia de la impugnación de los decretos de urgencia por el TGC, tenemos las opiniones favorables de GARCIA BELAUNDE y EGUIGUREN PRAELI. Entendemos con el maestro Domingo GARCIA BELAUNDE que "... si la acción de inconstitucionalidad procede contra todas las normas con valor de ley (y lo son también los decretos-leyes emanados de los gobiernos de facto), estimamos que los decretos de necesidad y urgencia deben ser considerados también entre las normas susceptibles de ser denunciadas de inconstitucionalidad, a través de la acción pertinente ante el Tribunal de Garantías Constitucionales". (Op.cit., p. 34). 
preso del Tribunal, que siga la corriente jurisprudencial de la Corte Suprema que reconoce el rango legal de los decretos supremos de necesidad y urgencia; y que, además, lo haga con relación a la interpretación extensiva que hemos esbozado.

Algunos han considerado a la acción popular como el recurso impugnatorio apropiado a la decretación de urgencia. Se ha dicho que, en el terreno práctico, el control sería similar, toda vez que la declaratoria de inconstitucionalidad de dicha acción tiene también efectos derogatorios generales a la norma cuestionada.

Quienes esto sostienen olvidan que dicho mecanismo sólo es procedente para impugnar a los decretos ordinarios y a las resoluciones de carácter general que contravengan la Constitución o las leyes (art. 295, tercer párrafo, de la Carta). En consecuencia, de aceptarse esta hipótesis se estaría negando el rango legal de los decretos de urgencia; cuando precisamente requieren de tal jerarquía para ir, de modo temporal, en contra de leyes formales por causas de extraordinaria necesidad.

\section{PROPUESTAS DE REGLAMENTACION DE LOS DECRETOS DE URGENCIA}

\subsection{Resumen explicativo: atando los cabos sueltos}

Antes de entrar a detallar las propuestas y conclusiones, quisiéramos reseñar brevemente los antecedentes conceptuales que les sirven de fundamento.

A lo largo de este trabajo hemos analizado tanto la naturaleza jurídica como los caracteres esenciales de las medidas de urgencia en la doctrina, el Derecho Comparado y la legislación peruana. De este estudio, se ha hecho visible una serie de deficiencias e insuficiencias de la regulación constitucional de la legislación de emergencia. En especial, con respecto a los siguientes items:

- Presupuesto de hecho habilitante;

- Rango legal;

- Forma legislativa adoptada; 
- Provisionalidad y control parlamentario posterior;

- Transitoriedad (vigencia);

- Ambito de aplicación: materia económico-financiera;

- Efectos sobre la normatividad preexistente (derogación o suspensión); y,

- Control concentrado de su constitucionalidad.

Sobre estas materias se enfocarán nuestras propuestas de reglamentación, procurando atar todos los cabos para darle correcta operatividad al instituto de los decretos supremos de urgencia.

\subsubsection{Cuando no reformar la Constitución es la premisa}

La finalidad central de nuestra propuesta es la de establecer mecanismos de reglamentación de la dogmática constitucional sobre el régimen jurídico de la decretación de urgencia que hagan posible su perfeccionamiento, sin necesidad de una previa reforma constitucional. Sin embargo, existen varias propuestas de reforma constitucional, como la que presentara el senador Enrique Bernales -del inciso 20-y la del senador Róger Cáceres Velásquez -sobre el inciso $1 \mathrm{del}$ artículo 298 (57).

Para tal efecto, consideramos que de una adecuada interpretación del instituto, así como de la sistemática de la Constitución, pueden cubrirse las graves omisiones que ella exhibe a este respecto.

Antes de pasar a la propuesta en sí, queremos adelantar que el primer borrador del Anteproyecto de Ley de Democratización de las Decisiones de Gobierno del Instituto Libertad y Democracia (ILD) -que propone una reglamentación en varios de sus artículos- será sometido a un breve estudio ulterior.

(57) A este respecto, vid. MELO-VEGA CASTRO, Jorge y FERNANDEZMALDONADO CASTRO, Guillermo. Las propuestas de reforma constitucional. En: Justicia, Revista de Política y Ley, No. 2, año 1, Lima, 1990, pp. 50-54. 
5.2 La reglamentación de los decretos presidenciales de necesidad y urgencia para adecuar la figura del inciso 20 del numeral 211 de la Constitución a su naturaleza juridica $y$ rasgos esenciales

\subsubsection{Presupuesto de hecho habilitante}

El presupuesto de hecho habilitante, según Torres del Morral (58), es "la excepcional y urgente necesidad que requiere ser solucionada". Como concepto jurídico indeterminado, la urgencia tendrá un alto componente político en su percepción; por lo que la adopción de la medida será un acto sujeto a la discrecionalidad del Presidente de la República, pero no así la determinación de la urgencia. Esta, en suma, estará condicionada a hechos concretos y a la interpretación doctrinal.

La urgencia, dijimos, constituye una de las hipótesis de la necesidad, cual es la de obrar rápidamente, al punto que tenga que soslayarse el procedimiento legislativo ordinario. El factor tiempo es, pues, elemento determinante.

Pero la urgente necesidad debe ir acompañada de otro requisito cuyo cumplimiento habilita la norma, cual es el interés nacional. En términos simples, entendemos con Hernández Berenguel (59), que "algo es de interés nacional cuando sirve en un momento determinado a los objetivos fundamentales del Estado y, por lo tanto, bajo el concepto de "interés nacional" no se puede invocar el inciso 20 del artículo 211 de la Constitución cuando en realidad, a través de la medida extraordinaria se está atendiendo un objetivo secundario o de menor trascendencia. (...) La medida extraordinaria tiene que responder a la utilidad, conveniencia o bienestar de la mayoría para que responda al interés nacional".

(58) TORRES DEL MORRAL. Op.cit.

(59) HERNANDEZ BERENGUEL. Op.cit., pp. 17-18. 


\subsubsection{Jerarquía de los decretos de urgencia}

A lo largo de todo este informe hemos sostenido con diversos argumentos el carácter de ley material que ostenta la legislación de emergencia. No vamos a reproducir de nuevo la polémica anotada; toca, más bien, proponer una solución para que no se repita en el futuro.

En tal sentido, consideramos que debe modificarse la Ley del Poder Ejecutivo (Decreto Legislativo No. 560), de tal forma que establezca, en el Título del Presidente de la República, que dentro de las facultades legislativas del primer mandatario se incluye -además de los decretos legislativos, los decretos supremos ordinarios y las resoluciones supremas- la posibilidad de emitir decretos supremos de urgencia al amparo del inciso 20 del numeral 211 de la Constitución; sancionando que tales medidas gozarán de rango legal.

De este modo, los decretos de urgencia adquirirían, dentro de las facultades legislativas del Poder Ejecutivo, una jerarquía superior a la de los decretos supremos ordinarios; esto es, se reconocería expresamente a lo que ya habíamos llegado por interpretación, en el sentido que son leyes en sentido material.

De otro lado, debería señalarse que dichos decretos son facultad originaria y privativa del Presidente de la República que no requiere de previa aprobación del Consejo de Ministros. Ello no implica que deban carecer de refrendación ministerial a efectos de la responsabilidad política que, como vimos en su oportunidad, no alcanza al primer mandatario.

De igual manera, debería prescribirse que en los considerandos de la norma se indique de manera precisa cuáles son las circunstancias de extraordinaria necesidad que habilita la utilización de dicha atribución presidencial excepcional. El cumplimiento de este requisito permitiría analizar la urgencia, pero no la haría incuestionable.

Lo antes expuesto no enerva la posibilidad de dictarse una ley que reglamente exclusivamente los decretos supremos de 
urgencia, pero dada la dificultad que una interpretación auténtica por parte del Congreso podría generar, la alternativa más expeditiva es la reseñada.

\subsubsection{Forma legislativa adoptada por los decretos de urgencia}

De manera complementaria, la modificatoria mencionada debería establecer que los decretos de urgencia se dictarán con el mismo ropaje jurídico que los decretos ordinarios esto es, como decretos supremos - pero con una denominación diversa: "decretos de urgencia". Por consiguiente, deberían contar con una numeración autónoma seguida de las siglas "DU", lo que haría más fácil su diferenciación e identificación, así como el control de su constitucionalidad.

\subsubsection{Provisionalidad y control parlamentario posterior}

En su oportunidad tratamos in extenso esta característica esencial de la legislación de emergencia. Vimos cómo nuestra Constitución había consignado un parco "dar cuenta al Congreso", y que, en nuestra opinión, era necesaria la fiscalización de estas normas por parte del Parlamento; que, de convalidar los decretos de urgencia, les otorgaría eficacia y rango legal definitivos.

Tómese nota que el requisito de la provisionalidad -que supone convalidación del Congreso-va íntimamente ligado a la jerarquía normativa de los decretos presidenciales de urgencia; puesto que, como viéramos en su momento, a partir de su ratificación adquieren rango legal definitivo, lo que no supone su conversión en leyes formales.

Dos vías podrian adoptarse para reglamentar el "con cargo de dar cuenta al Congreso" y delimitar de manera precisa la fiscalización del Parlamento.

- En primer término, la dación de una ley interpretativa por parte del Congreso de la República que disponga, como requisito 
esencial para la eficacia de los decretos de urgencia, la convalidación por parte de dicho poder del Estado. En consecuencia, la eficacia provisional de tales medidas duraría hasta producida la convalidación, luego de la cual adquiririan pleno y definitivo vigor.

Consideramos, asimismo, que dicha interpretación auténtica debería establecer que, de no mediar convalidación, la norma caduca. Los efectos de esta caducidad -como viéramos en su oportunidad-serían ex nunc, y no retroactivos como creemos que equivocadamente señala la Constitución italiana.

La razón de que la no convalidación suponga una caducidad y no una pérdida de efecto desde el principio, estriba en que la ratificación del Congreso - que supone la provisionalidad - es requisito de eficacia y no de validez. Así como en la incertidumbre que el efecto retroactivo ocasionaría en la esfera de las relaciones jurídicas y derechos producidos al amparo de la norma extraordinaria.

Sin embargo, y a fin de evitar la subsanación de posibles vicios generados por los efectos ex-nunc (no retroactivos) de la no ratificación, es necesario establecer mecanismos que permitan la impugnación de las relaciones jurídicas producidas durante la vigencia provisional del decreto ahora caduco.

Finalmente, de no permitirse el control parlamentario comentado, caeríamos en el contrasentido de aceptar que el Ejecutivo puede dictar normas con fuerza de ley sin ninguna participación fiscalizadora del Congreso; lo que, como hemos reiterado, resulta incompatible con el modelo legislativo de la Constitución de 1979.

- Una segunda alternativa podría estar por el lado de una modificatoria del Reglamento del Congreso, vía una resolución legislativa que adicione normas relativas al procedimiento que ha de entenderse por el "dar cuenta". Viene a colación, a este respecto, que el artículo 104 de la Carta -referido a los Convenios-, también menciona similar requisito. En consecuencia, podría dicha resolución legislativa normar ambos requerimientos, de acuerdo a la particular y distinta naturaleza 
de cada uno. El requisito de dar cuenta al Congreso contemplado en el numeral 231 - Capítulo VIII, Título IV, del Régimen de Excepción- merecería mención aparte, por tratarse de norma con un supuesto muy particular.

A este respecto, sólo nos queda añadir que, en ambas alternativas, debe fijarse un plazo perentorio dentro del cual el Ejecutivo debe cumplir con la obligación de presentar la medida de urgencia a la consideración del Congreso, así como el término dentro del cual éste deberá emitir opinión. En este sentido, por ejemplo, la Constitución italiana habla de 60 días, y la española de 30 .

Un tercer mecanismo, que no requiere de regulación alguna, está por el lado de un efectivo control parlamentario de hecho; como parece ha empezado a suceder en el actual régimen. Sin embargo, en la medida que tal sistema carece de coercibilidad, estaría sujeto a los devaneos de nuestra clase política.

En cuanto al órgano que ejerza efectivamente el control posterior, ya hemos visto que podría ser la Cámara de Diputados o incluso la Comisión Bicameral de Presupuesto del Congreso. Ello cuando el Parlamento está en ejercicio. En los periodos de receso, la Comisión Permanente sería el órgano facultado. Tales supuestos podrían incluirse en las normas reglamentarias a las que hemos hecho alusión.

\subsubsection{Vigencia transitoria de los decretos de urgencia}

Este punto ha sido, al igual que los anteriores, materia de largo estudio. Toca ahora esbozar nuestra propuesta para reglamentar esta característica connatural al instituto de los decretos de urgencia.

En la modificatoria a la Ley del Poder Ejecutivo podria establecerse, adicionalmente, que la vigencia provisional de las medidas extraordinarias ocurriría al día siguiente de su promulgación, salvo disposición diferente -recuérdese que estamos ante decretos supremos-, y que la vigencia definitiva -que está 
supeditada a la convalidación por el Congreso- estará sujeta a un periodo máximo de tiempo que podría ser, como establece el Anteproyecto del ILD, hasta de 6 meses. Al cabo de los cuales, de mantenerse el supuesto de hecho habilitante - la emergencia- se podría prorrogar la vigencia de las medidas; salvo que el Congreso juzgase pertinente darles permanencia, convirtiéndolas en leyes formales.

Para el caso de normas tributarias, cuya vigencia es mayormente anual, se podría establecer un plazo excepcional, que podría tener como límite máximo un año calendario, en caso que la medida sea contemporánea al inicio del año fiscal. Si la medida se dicta empezado el año fiscal, el plazo máximo sería lo que resta de éste, sin perjuicio de su inmediata entrada en vigencia.

Como resultará evidente, a diferencia de los decretos legislativos sobre materia tributaria, los decretos de urgencia referidos a ésta entran en vigor inmediatamente, pues buscan dar remedio a una situación extraordinaria.

\subsubsection{Alcance de la materia económico-financiera}

Con relación a las materias sobre las que pueden versar las medidas extraordinarias conferidas al Presidente, resulta oportuno, para evitar los ya habituales abusos en su utilización, restringirlas al campo de la hacienda pública. Para tal efecto, dentro de las modificaciones a la Ley del Poder Ejecutivo para reglamentar los decretos de urgencia debería establecerse que los mismos sólo pueden emanar del Ministerio de Economia y Finanzas, sin que ello enerve su numeración autónoma.

Sería pertinente, asimismo, que se dispusiera de una suerte de listado con las materias sobre las cuales el Presidente tendría competencia para legislar de ocurrir el supuesto de hecho habilitante. Esto impediría que se use la facultad extraordinaria para normar situaciones como las plazas de la Orquesta Sinfónica Nacional o los regímenes laborales de excepción como el PROEM. 


\subsubsection{Efectos sobre la normatividad preexistente: derogación o suspensión}

Ya hemos concluido que, a pesar de no fluir expresamente de la dogmática constitucional el sistema de suspensión de normas, éste resultaba lógica consecuencia del inciso 20, numeral 211 de la Carta Política.

Señalamos que de no aceptarse la suspensión, se producirían vacíos jurídicos cuando los decretos de urgencia contraviniesen normas legales, pues al ser éstos temporales o transitorios, una vez caduco su plazo de vigencia caeriamos en el absurdo - si se piensa que tiene efecto derogatorio- de requerir la dación de leyes exactamente iguales a las ahora inexistentes.

Consideramos, pues, que dentro de la modificatoria a la Ley del Poder Ejecutivo debe consignarse norma expresa que haga mención al hecho que de emitirse decretos supremos de urgencia que contravengan normas legales, se entenderá que la vigencia de estas últimas queda en suspenso hasta la desaparición de la causa que motivó la emisión de las medidas extraordinarias y que ahora produce su caducidad.

5.2.8 Control concentrado de la constitucionalidad de los decretos de urgencia: la posibilidad de su impugnación vía Acción de Inconstitucionalidad ante el Tribunal de Garantías Constitucionales

Nos hemos pronunciado, en su momento, a favor de la interpretación amplia del artículo 298 inciso 1 de la Constitución. No es lugar de repetir nuestro razonamiento. Solamente nos queda proponer que vía una modificatoria de la Ley Orgánica del Tribunal de Garantías Constitucionales - Ley No. 23385- se establezca que dentro del control concentrado de la constitucionalidad de las leyes, deba entenderse por éstas a toda norma con rango de ley.

En este orden de ideas, no sólo debe incluirse a los decretos de urgencia dentro del control jurisdiccional constitucional aludido, sino a los edictos y a toda otra norma con jerarquía legal por crearse. 
5.2.8.1 Comentario crítico de la resolución del TGC que declara "inadmisible" (sic) la impugnación de los decretos de urgencia vía Acción de Inconstitucionalidad de las Leyes

En su momento hicimos alusión a la conveniencia de que el Tribunal de Garantías Constitucionales acogiera y declarara la interpretación extensiva de la procedencia de la acción de inconstitucionalidad como medio de impugnación de los decretos de urgencia. Ya cuando este trabajo estaba terminado, apareció una resolución expedida por el TGC sobre el problema del control de la constitucionalidad de tales normas.

Con fecha 19 de octubre de 1990, se publicó en el Diario Oficial El Peruano la Resolución TGC que declara "inadmisible" la demanda de inconstitucionalidad interpuesta por 20 senadores contra el Decreto Supremo 057-90-TR, dictado al amparo del artículo 211 , inciso 20 de la Constitución. Previamente nos vemos en la obligación de manifestar que en ningún caso podría hablarse de "inadmisibilidad", sino más bien de improcedencia; toda vez que lo que está en discusión es la vía procesal adecuada, y no la ausencia de algún requisito de forma en la demanda.

Inclusive, la propia Ley Orgánica del Tribunal de Garantías Constitucionales, Ley 23385, en su artículo 30 establece de modo taxativo los casos de inadmisibilidad de las demandas de inconstitucionalidad. Tal precepto acoge lo que ya habíamos dicho, y añade los supuestos de haberse presentado el recurso fuera del plazo (6 años) o de haberse pronunciado ya el Tribunal de modo negativo sobre el fondo de un asunto similar.

A pesar de lo dicho, la resolución anotada señala que "la demanda adolece pues de defecto de forma, por no ser la vía para incoar la inconstitucionalidad del decreto supremo... la escogida ante el TGC por los accionantes". (El subrayado es nuestro).

Los argumentos de fondo que sostienen la denegatoria a la vía son dos:

- Que el artículo 298 inciso 1 tiene carácter taxativo y que, en 
consecuencia, no encontrándose el decreto supremo impugnado en ninguno de los supuestos señalados por la norma, la demanda que lo impugna resulta improcedente (para los vocales, "inadmisible");

- Uno de los votos singulares a favor de la "inadmisibilidad", afirma que el TGC carece de competencia para conocer la acción de inconstitucionalidad contra los decretos de urgencia; dado que no serían leyes ni tampoco tendrían fuerza de ley, porque la Constitución "cuando establece que una norma jurídica de inferior jerarquía a la ley tiene fuerza de ley, lo indica expresamente..." El argumento, que hasta aquí estaba dentro de los parámetros de la polémica, recurre, sin embargo, al ejemplo de los Convenios Colectivos, que según la Carta Política son ley entre las partes. Acaso por un descuido, no se percató el magistrado que la ratio de la norma constitucional sobre la negociación colectiva está en otorgar carácter obligatorio a los acuerdos laborales entre quienes los suscriben; pero no en concederles rango legal. Si bien los efectos de los convenios son generales entre quienes los celebran, ello en nada se parece a la generalidad de la norma legal, que es un supuesto diametralmente distinto.

Del mismo modo, nos parece cuestionable la misma opinión singular en cuanto señala que "todos los decretos supremos de carácter general son solamente decretos supremos de carácter general y nada más, y carecen de fuerza de ley". Más allá del tautológico razonamiento, negarle jerarquía legal a la decretación de urgencia basado en su ropaje jurídico, demuestra - creemosuna superficial aproximación al tema que nos ocupa.

Otro voto singular, a pesar de reconocer el rango legal de la normatividad de emergencia, afirma que son decretos de carácter general y que, por ello, la vía pertinente para su impugnación es la Acción Popular. Resulta curioso que reconociéndole jerarquía de ley a los decretos de urgencia, tal dictamen les niegue luego este valor al considerarles aplicable el mecanismo de impugnación de las normas generales con rango inferior al legal.

La resolución comentada podría, más allá de 
disquisiciones teóricas, generar graves consecuencias en la práctica. Así, existen a la fecha dos resoluciones del Fuero Laboral que, a su vez, han denegado la impugnación vía Acción Popular de los decretos supremos de urgencia que crean el Programa Ocupacional de Emergencia (PROEM). Dichas resoluciones fueron recurridas ante la Corte Suprema de Justicia, encontrándose en estado de sentencia. Como no existe manera de elucubrar una vía impugnatoria alternativa, de confirmar la Corte Suprema el fallo recurrido, la legislación de emergencia corre el riesgo de tornarse inatacable con efectos erga omnes.

Sólo un voto singular opinó favorablemente por la procedencia de la demanda. Para ello acudió al análisis del fenómeno de la función legislativa del Ejecutivo, generado a partir de la Segunda Guerra Mundial, así como a la moderna doctrina constitucional peruana y extranjera. Al señalar, conjuntamente con la doctrina nacional, la fuerza de ley de los decretos de urgencia, concluye por la procedencia de la vía incoada, como única forma de atacar la inconstitucionalidad de dichas medidas.

Creemos que el TGC ha perdido otra oportunidad invalorable de crear derecho. Ya Domingo García Belaunde (60) había manifestado sobre este órgano que "ha tenido siempre la enorme sabiduría de no pronunciarse nunca sobre conflictos delicados en materia constitucional". Confiamos, sin embargo, en que nuestro Tribunal Constitucional asumirá un rol más dinámico que le permita ubicarse a la vanguardia de la armonización constitucional.

6. EL PRIMER BORRADOR DEL ANTEPROYECTO DE LEY DE DEMOCRATIZACION DE LAS DECISIONES DE GOBIERNO DEL INSTITUTO LIBERTAD Y DEMOCRACIA (ILD) COMO ALTERNATIVA DE REGLAMENTACION DE LOS DECRETOS DE URGENCIA

El Anteproyecto del ILD trata la materia de los decretos de

(60) GARCIA BELAUNDE, Domingo. Si la Constitución no fuera política, no sería violada. Entrevista en: Diario El Nacional, edición del 16 de 
urgencia en sus artículos $88,89,90$ y 91 . Si bien el Anteproyecto introduce muchas de las modificaciones que hemos atribuido debe hacerse a la Ley del Poder Ejecutivo, omite algunos puntos trascendentes.

Así, el ILD considera que el Ejecutivo en la comunicación que deberá hacer al Congreso de la promulgación de la medida de emergencia - que debe ser dentro de los 3 dias siguientes- deberá incluir una explicación en torno a su extraordinariedad, naturaleza económico-financiera, de la urgencia y necesidad, y del interés nacional involucrado. De no cumplirse con el plazo establecido dice el precepto- el decreto caduca de pleno derecho.

Sin embargo, olvida al Anteproyecto la necesidad de establecer la provisionalidad de la decretación de urgencia; y en tal sentido, no dispone que el Congreso convalida la medida, dándole así eficacia definitiva. La caducidad del decreto también debería proceder si es que el Congreso, una vez que se le presenta la norma, no la ratifica. Al establecer el proyecto ILD una mera comunicación, soslaya el indispensable control parlamentario posterior, que es el complemento lógico y consustancial al instituto en análisis.

Ocurre que el Anteproyecto confunde la característica de provisionalidad con la de temporalidad o transitoriedad. Así to ha expresado el profesor Carlos Cárdenas -asesor jurídico del Anteproyecto-, quien en una serie de artículos publicados en el diario Página Libre (61) dijera que "las medidas extraordinarias tienen carácter provisional, pues han de referirse a acontecimientos transitorios".

Es más, de lo comentado por Cárdenas fluye que, para el ILD, los decretos de urgencia son susceptibles de derogación, cuando lo apropiado hubiese sido referirse a la convalidación o caducidad de

setiembre de 1989, pags. 15-18. Entrevista realizada por OQUENDO HERAUD, Sergio.

(61) CARDENAS QUIROS, Carlos. Los decretos de urgencia. En: Diario Página Libre, publicado en tres partes el 20, 21 y 23 de marzo de 1990, sección Opinión.. 
dichas medidas. Cabría, en todo caso, hablar de derogación si el referido decreto hubiese sido previamente ratificado por el Congreso.

Otra deficiencia del Proyecto del ILD es que no zanja de una vez por todas el problema de la jerarquía legal de los decretos de urgencia; tan sólo parece presumirle tal rango. Esto es en principio correcto, pero hubiese sido aconsejable incluirlo de manera expresa.

De esto se deriva otra deficiencia: el problema del control jurisdiccional constitucional de las medidas de emergencia.

Adicionalmente, el Anteproyecto no hace referencia alguna a qué sucede con la normatividad preexistente en caso de existir colisión con el decreto de urgencia; esto es, si la norma legal colisionada es modificada, derogada o queda en suspenso.

Tampoco precisa el Anteproyecto la materia económicofinanciera, por lo que bastaría para éste que el Ejecutivo, al momento de informar de manera explicada al Congreso, le atribuya tal naturaleza a una situación que de por sí no la tiene.

Por último, el ILD considera que necesariamente los decretos de urgencia deberán aprobarse en Consejo de Ministros. Aduce que ésta ha sido la práctica corriente. Ello no obstante, al encontrarnos ante una facultad originaria y privativa del Presidente, bien podría éste promulgar una medida de emergencia sin necesidad de contar con el voto aprobatorio de su Consejo Ministerial; pues le sería suficiente contar con la refrendación del ministro de Economía y Finanzas.

Consideramos, no obstante todas estas deficiencias, que por estar frente a un "primer borrador", de perfeccionarse el Anteproyecto del ILD y llegar a ser ley, podría ser un buen instrumento para reglamentar la legislación de emergencia y acabar, de una buena vez, con las dudas que aún muchos cobijan. 
BIBLIOGRAFIA BASICA UTILIZADA

ALEGRE AVILA, Juan Manuel

La viabilidad constitucional del Decreto-Ley en materia tributaria y la regulación del derecho de propiedad. En: Revista de administración pública, No. 105, Centro de Estudios Constitucionales, Madrid, 1985.

ASTARLOA HUARTE-MENDICOA, Ignacio

Teoría y práctica del Decreto-ley en el ordenamiento español. En: Revista de administración pública, No. 106, Centro de Estudios Constitucionales, Madrid, 1985.

BERNALES BALLESTEROS, Enrique

El Parlamento por dentro. DESCO, Lima, 1984.

BERNALES BALLESTEROS, Enrique

El funcionamiento del sistema político en la Constitución de 1979. En: La Constitución diez años después. Fundación Friedrich Naumann, primera edición, Lima, 1989.

BERNALES BALLESTEROS, Enrique/ RUBIO CORREA, Marcial Constitución y sociedad politica. Ediciones Mesa Redonda, primera edición, Lima, 1983; así como la tercera edición, Lima, 1988.

BOREA ODRIA, Alberto

Exposición en el Colegio de Abogados de Lima sobre el Tribunal de Garantias Constitucionales. En: Revista del Foro.

BISCARETTI DI RUFFIA, Paolo

Derecho constitucional. Editorial Tecnos, Madrid, 1973.

CARDENAS QUIROS, Carlos

Los decretos con fuerza de ley. En: Diario Página Libre, ediciones del 20, 21 y 23 de marzo de 1990, sección editorial, Lima. 
CORTES GENERALES DE ESPAÑA

Boletín de jurisprudencia constitucional, No. 23, Madrid, 1983.

CHIRINOS SOTO, Enrique

La nueva Constitución al alcance de todos. AFA Editores, tercera edición, Lima, 1984.

DE LA PUENTE Y LAVALLE, Manuel

Las medidas extraordinarias. En: Revista Peruana del Derecho de la Empresa, No. 20, 1986.

EGUIGUREN PRAELI, Francisco

Normas contrarias a la Constitución y la ley. En: Revista del Foro, año LXXI, No. 1, Colegio de Abogados de Lima, Lima, 1984.

EGUIGUREN PRAELI, Francisco

Los decretos de necesidad y urgencia en relación a la atribución presidencial de dictar medidas extraordinarias contenida en el inciso 20 del artículo 211 de la Constitución. En: Derecho, No. 40, Fondo Editorial PUC, Lima, diciembre de 1986.

EGUIGUREN PRAELI, Francisco

El fortalecimiento de las funciones legislativas del gobierno: decretos legislativos y decretos presidenciales de urgencia. En:La Constitución Peruana de 1979 y sus problemas de aplicación. Cultural Cuzco Editores, Lima, 1987.

EGUIGUREN PRAELI, Francisco

Los retos de una democracia insuficiente. Comisión Andina de Juristas/ Fundación Friedrich Naumann, primera edición. Lima, 1990.

GARCIA BELAUNDE, Domingo

Funciones legislativas del Ejecutivo moderno: el caso peruano. En: Lecturas sobre temas constitucionales \# 3, Comisión Andina de Juristas, Lima, 1989.

GARCIA BELAUNDE, Domingo

Si la Constitución no fuera política, no sería violada. Entrevista por Sergio Oquendo Heraud en: Diario El Nacional, edición del 16 de setiembre de 1989 . 
GASCON HERNANDEZ, Juan

Problemas actuales del Decreto-ley. En: Revista de administración pública, No. 15, Instituto de Estudios Políticos, Madrid, 1954.

HERNANDEZ BERENGUEL, Luis

El principio de legalidad y las medidas extraordinarias que se pueden dictar mediante Decreto Supremo en materia Economica y Financiera. En: Cuadernos tributarios, No. 1, IFA, Lima, 1986.

INSTITUTO LIBERTAD Y DEMOCRACIA

Primer Borrador del Anteproyecto de Ley de Democratización de las Decisiones de Gobierno.

LANDA ARROYO, César

Citado por EGUIGUREN. Los retos...

Leyes constitucionales (traducciones), Editorial Taurus, Madrid, 1959.

MEDRANO CORNEJO, Humberto

Acerca del principio de legalidad en el derecho tributario. En: Revista del Instituto Peruano de Derecho Tributario, No. 12, Lima, junio de 1987.

MELO-VEGA CASTRO,Jorge/FERNANDEZ-MALDONADO CASTRO, Guillermo

Las propuestas de reforma constitucional. En: Justicia, Revista de Política y Ley, No. 2, año 1, Lima, 1990.

PACHECO BARANDIARAN, María del Rosario

Los decretos de urgencia y la Constitución de 1979. Tesis PUC, Lima, 1986.

PACHECO BARANDIARAN, María del Rosario

Los decretos de urgencia y un vacio en la Constitución de 1979. En: Themis, Revista de Derecho, segunda época, No. 6, Lima, 1987.

PAREJA PFLUCKER, Piedad

Atribuciones constitucionales del Presidente de la República. Ediciones Rikchay, Lima, 1987. 
PAREJA PAZ-SOLDAN, José

Derecho constitucional peruano y la Constitución de 1979. Ediciones Justo Valenzuela, tercera edición, Lima, 1984.

POWER MANCHEGO-MUÑOZ, Jorge

Constitución y justicia. Editorial Andina, Lima, 1984.

QUIROGA LEON, Anibal

El sistema de justicia constitucional en el Perú. En: Lecturas sobre temas constitucionales \# 2, Comisión Andina de Juristas, Lima, junio de 1988.

RUBIO LLORENTE, Francisco

Rango de ley, fuerza de ley, valor de ley. En: Revista de administración pública, No. 100, Centro de Estudios Constitucionales, Madrid, 1983.

SACHICA, Luis Carlos

El control de constitucionalidad y sus mecanismos. Editorial Temis, tercera edición, Bogotá, 1988.

SALAS, Javier

Los Decretos-leyes en el ordenamiento jurídico español. En torno a la urgencia. En: Revista de administración pública, No. 51 , Instituto de Estudios Políticos, Madrid, 1966.

TORRES DEL MORRAL, Antonio

Principios de derecho constitucional español. Atomo ediciones, Madrid, 1986.

TRIBUNAL DE GARANTIAS CONSTITUCIONALES

Resolución del expediente 004-90-I/TGC, publicada en el Diario Oficial El Peruano, el 19 de octubre de 1990.

VELASCO LOZADA, Ana Rosa

La Constitución peruana de 1979: atribuciones legislativas de los órganos Ejecutivo y Legislativo. Tesis PUC, 1988.

ZOLEZZI MOLLER, Armando

El inciso 20 del artículo 211 de la Constitución y la tributación. En: Revista del Instituto Peruano de Derecho Tributario, No. 10, Lima, junio de 1986.

418 